\title{
Geospatial blending to improve spatial mapping of precipitation with high spatial resolution by merging satellite- and ground based data
}

\author{
-Jongjin, Baik ${ }^{1}$, Jongmin, Park $^{2}$, Dongryeol, Ryu $^{3}$, and Minha, Choi ${ }^{2} *$ \\ ${ }^{1}$ School of Civil, Architectural and Environmental System Engineering, Sungkyunkwan \\ University, Sungkyunkwan University, Suwon, 440-746, Republic of Korea \\ 2 Water Resources and Remote Sensing Laboratory, Department of Water Resources, \\ Graduate School of Water Resources, Sungkyunkwan University, Suwon, 440-746, Republic \\ of Korea \\ ${ }^{3}$ Department of Infrastructure Engineering, The University of Melbourne, Parkville, Vic. 301 \\ 0, Australia

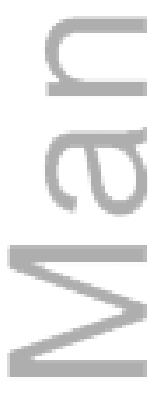

$$
\begin{gathered}
\begin{array}{c}
\text { jibaek@skku.edu } \\
\text { jmpark1@skku.edu }
\end{array} \\
\text { dryu@unimelb.edu.au } \\
\underline{\text { mhchoi@skku.edu }}
\end{gathered}
$$

Running head : Merging methods of ground and satellite based precipitation.

Submitted to the Hydrological Processes, September 5, 2015

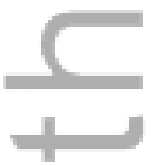

*Corresponding author

Associate Professor

Department of Water Resources, Graduate School of Water Resources, Sungkyunkwan University, 2066, Seobu-ro, Jangan-gu, Suwon, Gyeonggi-do, 440-746, Republic of Korea.

Tel: 82-31-290-7527

Fax: 82-31-290-7549

This is the author manuscript accepted for publication and has undergone full peer review but has not been through the copyediting, typesetting, pagination and proofreading process, which may lead to differences between this version and the Version of Record. Please cite this article as doi: 10.1002/hyp.10786

This article is protected by copyright. All rights reserved. 


\section{Email: $\underline{\text { mhchoi@skku.edu }}$}

\section{Highlights}

1. GDA, GRA and CM methods were used for merging ground-based rainfall with COMS

RI.

2. Merged rainfall was improved on the change of time interval and raingauge density.

3. CM performed best with high spatial heterogeneous rainfall in low raingauge density .

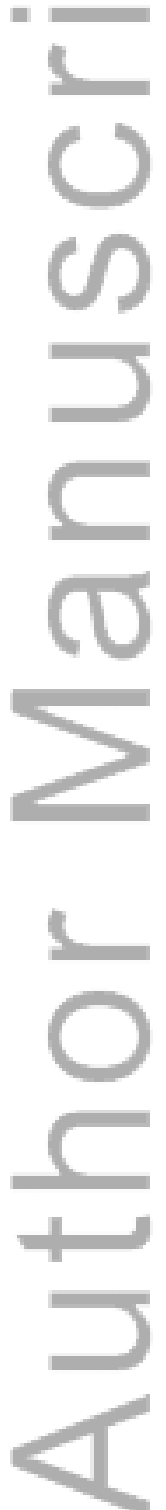

This article is protected by copyright. All rights reserved. 


\begin{abstract}
Estimating accurate spatial distribution of precipitation is important for understanding the hydrologic cycle and various hydro-environmental applications. Satellite-based precipitation data have been widely used to measure the spatial distribution of precipitation over large extents, but an improvement in accuracy is still needed. In this study, three different merging techniques (Conditional Merging, Geographical Differential Analysis, and Geographical Ratio Analysis) were used to merge precipitation estimations from Communication, Ocean, and Meteorological Satellite (COMS) Rainfall Intensity (RI) data and ground-based measurements. Merged products were evaluated with varying rain gauge network densities and accumulation times. The results confirmed that accuracy of detecting quantitative rainfall was improved as the accumulation time and network density increased. Also, the impact of spatial heterogeneity of precipitation on the merged estimates were investigated. Our merging techniques reproduced accurate spatial distribution of rainfall by adopting the advantages of both gauge and COMS estimates. The efficacy of the merging techniques was particularly pronounced when the spatial heterogeneity of hourly rainfall, quantified by variance of rainfall, was greater than $10 \mathrm{~mm}^{2} /$ accumulation time ${ }^{2}$. Among the techniques analyzed, Conditional Merging performed the best, especially when the gauge density was low. This study demonstrates the utility of the COMS RI product, which has a shorter latency time (1 hour) and higher spatio-temporal resolution (hourly, $4 \mathrm{~km}$ by $4 \mathrm{~km}$ ) than other widely used satellite precipitation products, in estimating precipitation using merging techniques with ground-based point measurements. The outcome has important implications for various hydrologic modeling approaches, especially for producing near real-time products.
\end{abstract}


Keywords: COMS; CM; GRA; GDA; Ordinary Kriging

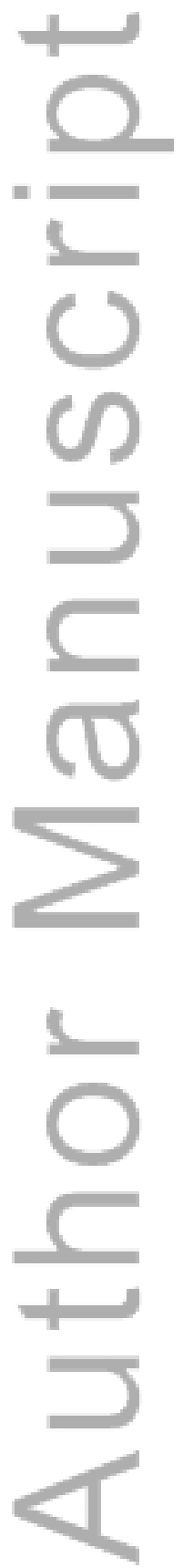

This article is protected by copyright. All rights reserved. 


\section{Introduction}

Accurately recording the spatial distribution of precipitation is critical for reliable predictions in earth science, hydrology, climatology, and agriculture (e.g., Hwang et al., 2011). Many researchers have analyzed and developed various methodologies to obtain accurate spatio-temporal precipitation data using various sources such as rain gauges, ground-based radar, and satellites (Sene, 2013; Michaelides, 2008; Crochet et al., 2007).

Acquisition of precipitation data is conventionally limited to ground-based measurements via, for example, automatic weather stations. Ground-based systems can provide accurate measurements and reasonable areal estimation in the areas adjacent to them, but the quality of gauge networks over a large spatial extent is restricted by high spatial and temporal variability of precipitation, the influence of terrain, and unrepresentative distribution of gauge network (Andréassian et al., 2001; Cheng et al., 2008; Adhikary et al., 2014). As a result, researchers have used various spatial interpolation techniques including Thiessen polygons, inverse distance weighting, ordinary Kriging (OK), Kriging with external drift (Hudson and Wackernagel, 1994; Goovaerts 2000), and co-Kriging (Bárdossy and Lehmann 1998; Lloyd, 2005), as well as other techniques based on splines (Hutchinson, 1998) in order to estimate spatial pattern of precipitation from rain gauge. Application of those methods to reproduce spatio-temporal variations in precipitation, however, introduces interpolation/extrapolation errors when network density is limited (Goudenhoofdt and Delobbe, 2009; Javanmard et al., 2010). Therefore, areal average precipitation estimated only from point measurements can insufficiently represent the accurate distribution of precipitation (Ebert et al., 2007; Duethmann et al., 2013). 
Remote sensing techniques have been used as an alternative method to estimate precipitation at both the regional and global scales. Weather radar has been used to observe spatio-temporal patterns of precipitation including the Next-Generation Radar system and the X-band polarimetric radar network (Wright et al., 2013; Germann et al., 2006; Miki et al., 2008). In Korea, the Korea Meteorological Administration (KMA) operates 12 radar stations to monitor and predict extreme weather and floods over the Korean peninsula (You et al., 2014). However, various studies have revealed that estimating precipitation from radar also poses significant problems; electronic miscalibration (Goudenhoofdt and Delobbe, 2009), signal contamination by non-meteorological echoes or range effect (Fries et al., 2014), beam blocking by natural impediments (e.g., mountain region, surrounding hills with similar or higher altitudes), and the variance in the reflectivity and rainfall rate relationships (Fornasiero et al., 2006; Lim et al., 2014; Yoo et al., 2013; Jameson and Kostinski, 2002; Vulpiani et al., 2012; Qin et al., 2014).

Satellite-based precipitation measurement has emerged to overcome the limitations of raingauge and radar-based precipitation data. It can be divided into two categories depending on the sensor characteristics. Low-earth orbiting satellites containing passive microwave (PM) sensors, such as the Tropical Rainfall Measuring Mission (TRMM), National Oceanic and Atmospheric Administration (NOAA) weather satellites, and Defense Meteorological Satellite Program, have been widely used for their advantages in representing the direct physical relation between scattered upwelling radiation and hydrological components (Feidas et al., 2009; Levizzani et al., 2001; Joyce et al., 2004). Given their popularity for global scale applications, the TRMM precipitation products have been extensively evaluated and used in 
various regions (Huffman et al., 2007; Xue et al., 2013; Ochoa et al., 2014). However, precipitation estimated from PM sensors is typically available at coarse spatial resolutions $(\sim 25 \mathrm{~km})$ with sparse overpass for each satellite (twice a day). The Global Precipitation Measurement (GPM) is a successor of TRMM launched as the joint mission of various space agencies throughout the world such as (NASA, JAXA, CNES, ISRO, NOAA, and EUMETSAT. One of the main objectives of GPM Mission is to determine the structure and magnitude of precipitation for comprehensive understanding of water and energy cycle with improved overpass frequency (Huffman et al., 2013; Hou et al., 2014). But coarse spatial resolution $(\sim 10 \mathrm{~km})$ remains an issue when using GPM. Infrared geostationary satellites, provide reasonable estimates over large spatial extents with a higher temporal resolution, but the physical relation between the infrared signals and precipitation is relatively weak (Feidas et al., 2009). Previous studies used various geostationary satellites to estimate precipitation (Vicente et al., 1998; Kuligowski, 2002; Mecikalski and Bedka, 2006; Zhuge et al., 2015). Although the two types of satellite-based precipitation data have unique advantages in monitoring large spatial areas for long periods, those products often contain large errors that originate from topographic features, insufficient or inconsistent sensitivity between the electromagnetic signal and clouds, precipitation retrieval algorithms, and unobserved data during extreme precipitation (Chen et al., 2013; Kidd et al., 2003; Hong et al., 2006; AghaKouchak et al., 2012; Duncan and Biggs, 2012; Müller and Thompson, 2013).

To overcome the limitations of current satellite products, researchers have developed various merging techniques that combine precipitation from point measurements and remote sensing techniques in order to take advantage of complementary merits from each dataset 
(Woldemeskel et al., 2013; Sinclair and Pegram, 2005). In fact, merging techniques have been widely adopted for precipitation estimates using ground-based radar (Creutin et al., 1998). Karjewski (1987) improved the accuracy of rainfall data and reduced bias by merging rain gauge and radar datasets. Berndt et al. (2014) applied a conditional merging technique proposed by Ehret (2003) to combine rain-gauge and radar-based precipitation data. Ebert et al. (2007) also developed a merging technique to combine a mean precipitation field interpolated from rain-gauge and radar-based information containing the spatial variability of precipitation. Šálek et al. (2004) combined radar-based quantitative precipitation estimation and ground-based precipitation using a simplified double optimal estimation method. The result indicated that merged rainfall can be useful for hydrological applications, though substantial errors in radar-based data might arise because of the bright-band and attenuation effects

Similar efforts have been made to merge satellite-based precipitation products with ground observations (Vila et al., 2009;Shin et al., 2011; Blacutt et al., 2015). Rozante et al. (2010) blended precipitation observed from TRMM 3B42RT and ground stations using the Barnes objective analysis method (Barnes, 1973). Li and Shao (2010) developed a strategy to combine TRMM 3B42 and ground-based measurements using a nonparametric kernel smoothing technique. Chappell et al. (2013) also utilized Normal Score Transform and geostatistical approaches to combine the TRMM 3B42 RT and gauge datasets in Australia. Xie and Xiong (2011) developed a conceptual model for combining bias-corrected CMORPH by probability density function and gauge datasets using Optimal interpolation technique. Therefore, the specific objectives of this study are: 
(1) Improving the spatial mapping of precipitation with high spatial resolution (i.e., $1 \mathrm{~km}$ ) by merging ground- and satellite-based precipitation retrieved from the Communication, Ocean, and Meteorological Satellite (COMS) and at the Namhan watershed using three different approaches: Geographic Ratio Analysis (GRA; Duan and Bastiaanssen, 2013), Geographic Differential Analysis (GDA; Cheema and

= Bastiaanssen, 2012), and Conditional Merging (CM)

(2) Cross-validating the merged precipitation datasets in different accumulation times (124 hours) and rain gauge densities

(3) Evaluating the merged precipitation datasets for varying degrees of spatial heterogeneity in order to comprehensively assess their efficiency of accumulation times and rain gauge densities.

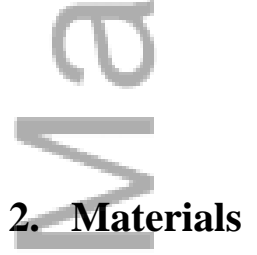

\subsection{Study area and rain gauge data}

The downstream of the Namhan River watershed (located within $127^{\circ} 09^{\prime} \mathrm{E}-127^{\circ} 54^{\prime} \mathrm{E}$ and $36^{\circ} 05^{\top} \mathrm{N}-37^{\circ} 42^{\prime} \mathrm{N}$ ) on the Korean peninsula was selected as our study area. Fig. 1 shows the geographical location of the study area and the 44 rain gauges in and around the catchment. Those rain gauges are managed by the KMA and Ministry of Land, Infrastructure and Transport.

The Namhan River watershed contains 19 sub-watersheds with an approximate total area 
of $2,072.72 \mathrm{~km}^{2}$. The average and maximum elevations of the watershed are $148.21 \mathrm{~m}$ a.s.l. and 1,133 m a.s.l., respectively. The southern part of the study area, a major rice production region in Korea, is predominantly cropland. The northern part of the study area is a mixed forest. The study area shows continental climate patterns, with high temperature and humidity in the summer and low temperature and humidity during the winter. Average annual

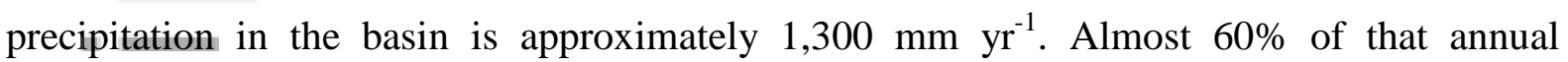
precipitation occurs during the summer monsoon season (June-July) and only $\sim 10 \%$ of it occurs in the pre-monsoon season (April-May). In addition, various researchers analyzed the significant increasing and decreasing trend of precipitation in summer and spring season, respectively, which also significantly influenced on the seasonal streamflow and spring drought condition (Bae et al., 2008; Jung et al., 2012). Thus, the study area undergoes an intense spring drought that significantly influences vegetation growth (Kim et al., 2005). Therefore, efficient water management with accurate precipitation data is essential. Based on these features, hourly precipitation data at 44 rain gauges were obtained from the Water Management Information System (http://www.wamis.go.kr/) during April 21 to May 21, 2011.

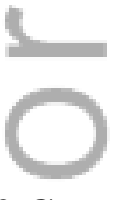

\subsection{Communication, Ocean and Meteorological Satellite (COMS) Rainfall Intensity (RI) data}

The Meteorological Image (MI) sensor onboard the geostationary COMS was launched on July 27,2010, as part of the long-term National Space Development project. MI is located at a longitude of $128.2^{\circ} \mathrm{E}$ and has similar instrument specifications as the Geostationary 
Operational Environmental Satellite 8-13 (U.S.) and the Meteorological Satellite-2 (Japan) with five bands (visible, shortwave infrared, water vapor, infrared1, and infrared2) collected every 15 minutes (Baik and Choi, 2015). The COMS Data Processing System estimates various datasets, including rainfall intensity, land surface temperature, and sea surface temperature, and makes them available at the National Meteorological Satellite Center (http://nmsc.kma.go.kr/).

The COMS RI algorithm estimates precipitation by measuring the brightness temperature observed at the top of a cloud caused by the shallow penetration depth of infrared channels into cloud layers. In particular, this algorithm uses the relationship between the vertical cloud temperature (collected by the Regional Data Assimilation and Prediction System) and cloud types (using datasets from the Meteosat Second Generation and International Satellite Cloud Climatology Project) to estimate rainfall intensity. The probability matching method from both Atlas et al. (1990) and Crosson et al. (1996) was used to estimate rainfall intensity and estimated rainfall intensity was cross-validated by comparing it with the ground-based rainfall data and brightness temperatures of the Special Sensor Microwave Imager. The COMS RI is produced in 15-minute time intervals at a spatial resolution of $4 \mathrm{~km}$ by $4 \mathrm{~km}$. For comparison with precipitation observed on the ground, we converted the COMS RI into an hourly scale. More detailed descriptions are given by Lee and Ryu (2012) and Baik and Choi (2015).

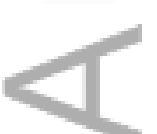

\section{Methodology}




\subsection{Geostatistical merging techniques}

\subsubsection{Conditional Merging (CM) technique}

The CM technique, introduced in Ehret (2003) and Sinclair and Pegram (2005), has been used to merge precipitation data observed from radar and ground-based measurements, and then OK has been used to obtain information about precipitation observations (Sinclair and Pegram, 2005; Frezghi and Smithers, 2008; Berndt et al., 2014). Thus, defining a semivariogram to characterize the spatial variability of precipitation is an important step in conducting $\mathrm{CM}$. For the operation of $\mathrm{OK}$, it is assumed that a theoretical semivariogram is fitted to the experimental semivariogram based on normally distributed precipitation datasets (Berndt et al., 2014). The experimental variogram can depict spatial correlation at various distances by estimating the semi-variance (i.e., the average degree of dissimilarity) between unsampled and sampled data points (Goudenhoofdt and Delobbe, 2009; Ly et al., 2011). The experimental semi-variance for the pair of datasets with a separation distance of $h, \hat{\gamma}(h)$ is:

$$
\hat{\gamma}(h)=\frac{1}{2 N(h)} \sum_{i=1}^{N(h)}\left[z\left(x_{i}\right)-\mathrm{z}\left(x_{i}+h\right)\right]^{2}
$$

where $x_{i}$ and $x_{i}+h$ represent the location of the dataset with a separation distance of $h$, and $N(h)$ represents the number of pairs with a distance of $h . z\left(x_{i}\right)$ and $z\left(x_{i}+h\right)$ are the values of datasets at locations $x_{i}$ and $x_{i}+h$, respectively; $i$ is the number of data values. After calculating the experimental semivariogram, it was fitted to theoretical semivariogram by using the weighted least squares to estimate the best variogram parameters such as nugget, sill, and range (Robinson and Metternicht, 2006). Among the various theoretical semivariograms, an isotropic exponential model was selected following Adhikary et al. 
(2014), and ignored the potential anisotropy in the semi-variance to simplify the estimation.

In this study, the CM technique follows the procedure below:

(a) Compute the interpolation field $(1 \mathrm{~km})$ using $\mathrm{OK}$ from ground-based precipitation data.

(b) Subsampling the original COMS RI data by dividing each $4 \mathrm{~km}$ grid into 16 uniform sub-grids (i.e., $4 \mathrm{~km}$ to $1 \mathrm{~km}$ ) in order to depict a more concrete spatial distribution of precipitation.

(c) Extract the values corresponding to the observation gauge used in (a) from the downscaled COMS RI grid cells.

(d) Estimate the interpolation field $(1 \mathrm{~km})$ by applying OK to the grid cells extracted in (c).

(e) Estimate the error characteristics of the precipitation field, which is defined as (b)-(d), assuming that the COMS RI data represent the truth field.

(f) Obtain the merged precipitation field $(1 \mathrm{~km})$ by adding the error characteristics of precipitation field (e) to the interpolation field from ground-based precipitation data

\section{(a).}

More detailed descriptions are given by Ehret (2003), Sinclair and Pegram (2005), Frezghi and Smithers (2008), and Berndt et al. (2014).

3.1.2 Geographical Differential Analysis (GDA) and Geographical Ratio Analysis (GRA)

\section{methods}

GDA, proposed by Cheema and Bastiaanssen (2012), has been used to reduce the uncertainties of precipitation data from satellites (Laurent et al., 2013). GDA improves the quality of precipitation data by calculating the differences in the spatial distributions from various datasets, which are then used for merging. In this study, GDA was calculated with 
gauge- and satellite-based precipitation data through the following process:

$$
\begin{array}{r}
\Delta R_{(i, j)}=R_{\text {model },(i, j)}^{1 k m}-R_{\mathrm{Obs},(i, j)} \\
R_{\mathrm{GDA},(i, j)}^{1 k m}=R_{\text {model },(i, j)}^{1 k m}-\Delta R_{\mathrm{IP},(i, j)}^{1 k m}
\end{array}
$$

Where $\Delta R_{(i, j)}$ is the difference between ground- and satellite-based precipitation in the grid cells corresponding to the gauge stations, and $R_{\text {model, }(i, j)}^{1 \mathrm{~km}}$ and $R_{\mathrm{Obs},(i, j)}$ are the satellite- and gauge-based precipitation data at the corresponding pixels of the gauge stations, respectively. $R_{\mathrm{GDA}_{3}(i, j)}^{1 k m}$ is the final merged precipitation, and $\Delta R_{\mathbf{I P}_{*}(i, j)}^{1 k m}$ interpolates $\Delta R_{(i, j)}$ using OK.

GRA uses the geographical ratio, defined as the ratio of the precipitation observed from the gauge and satellite, to improve data quality (Jia et al., 2011; Duan and Bastiaanssen, 2013). GRA was computed as:

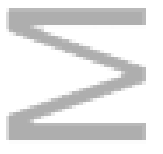

$$
\begin{array}{r}
R_{\text {GRA_Ratio }(i, j)}^{1 k m \_ \text {point }}=\frac{R_{\text {Obs. }(i, j)}}{R_{\text {model }(i, j)}^{1 k m}} \\
R_{\mathrm{GRA}(i, j)}^{1 k m}=R_{\text {model }(i, j)}^{1 k m} \times R_{\mathrm{GRA} \_ \text {Ratio }(i, j)}^{1 k m_{2} O K}
\end{array}
$$

Where $R_{\text {GRA_Ratio(i,j) }}^{1 \mathrm{~km} \text { point }}$ stands for the ratio of the gauge- and satellite-based precipitation at the gauge stations. $R_{\text {GRA_Ratio(i,j) }_{1}^{1 k m} \text { iK }}$ is the spatially interpolated ratio map using the OK method, and $R_{\mathrm{GRA}(i, j)}^{1 \mathrm{~km}}$ is the final calibrated precipitation. More detailed descriptions of GRA are given by Jia et al. (2011), Cheema and Bastiaanssen (2012), and Duan and Bastiaanssen (2013). 


\subsection{Model validation}

Many previous studies, e.g., Berndt et al. (2014), Goudenhoofdt and Delobbe (2009), and Krajewski (1987), have indicated that rain gauge density and accumulation time are important in improving performance. To analyze the effect of the network density ( $\mathrm{S} 0$ to $\mathrm{S} 4$ ) and the accumulation time (1 to 24 hours), 25 scenarios with varying numbers of gauges and accumulation time were used (Fig. 2). Before selecting gauge stations for the five scenarios, 44 sites were divided into two groups: 35 stations for merging and 9 stations for validation. Then, stations for each scenario were randomly selected. Scenario 0 (S0) denotes the case with the minimum number of stations, and the number of stations increases as the scenario number rises. In addition, precipitation estimated in each scenario was divided into five different accumulation times $(1,3,6,12$, and 24 hours) to examine the effect of accumulation time on the accuracy of the merged precipitation datasets.

Cross-validation has been widely used for model validation in precipitation studies (Nalder and Wein, 1998). In this study, a modified cross-validation based on Berndt et al. (2014) was employed by defining five different scenarios and accumulation time steps. A separate set of nine evaluation sites, which were not used in the merging, were selected to evaluate the precipitation data produced from the different merging techniques and Kriging. The following statistics were used for evaluation: mean error (ME), root mean squared error (RMSE), correlation coefficient ( $\mathrm{r}$ ), and relative bias, which are defined as:

$$
M E=\frac{1}{N} \sum_{i=1}^{N}\left(S_{i}-G_{i}\right)
$$




$$
\begin{gathered}
R M S E=\sqrt{\frac{1}{N} \sum_{i=1}^{N}\left(S_{i}-G_{i}\right)^{2}} \\
r=\frac{\sum_{i=1}^{N}\left(S_{i}-\bar{S}\right)\left(G_{i}-\bar{G}\right)}{\sqrt{\sum_{i=1}^{N}\left(S_{i}-\bar{S}\right)^{2}} \sqrt{\sum_{i=1}^{N}\left(G_{i}-\bar{G}\right)^{2}}} \\
\text { Relative bias }(\%)=\frac{\sum_{i=1}^{N} G_{i}-S_{i}}{\sum_{i=1}^{N} G_{i}} \times 100
\end{gathered}
$$

where $G$ is the observed value at a ground-based rain gauge; $S$ is the merged precipitation at the corresponding pixel; $\bar{S}$ and $\bar{G}$ are the average of $G$ and $S ; \mathrm{N}$ is the sample size; and $i$ denotes the $i$ th value of the ground-based and merged precipitation datasets.

In addition, the probability of detection (POD) and false alarm ratio (FAR) were used to assess the detection capabilities. POD, also known as the hit rate, represents the probability of rainfall detection. FAR is defined as the ratio of the false detection of rainfall to the total number of rainfall events (Nasrollahi, 2015). FAR and POD values are defined as follows:

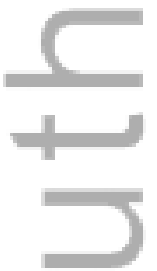

$$
\begin{gathered}
F A R=\frac{F}{H+F} \\
P O D=\frac{H}{H+M}
\end{gathered}
$$

where $H$ represents the number of both observed and estimated precipitation events, and $F$ is the number of false alarms when observed precipitation was below the threshold and estimated precipitation was above threshold. $M$ is the number of events in which the 
estimated precipitation was below the threshold and observed precipitation was above the threshold. The POD and FAR values are dimensionless numbers ranging from 0 to 1 . Precipitation threshold (event/no event) was set to $0.5 \mathrm{~mm} /$ accumulation time.

\section{Results \& Discussion}

\subsection{Validation of precipitation observed from COMS}

Fig. 3 shows the time series and probability distribution function (PDF) of the mean hourly precipitation from the ground-based measurements and the COMS RI. The PDF can provide an insight into error in accordance with rainfall rate for analyzing precipitation characteristics (Chen et al., 2013; Huang et al., 2013; Vila et al., 2009). As shown in Fig. 3(a), The overall trend of two datasets showed good correspondence. However, several discrepancies occurred. For example, on 3-6 May, the rain gauges measured no precipitation, whereas COMS detected precipitation. Also, on 9-12 May, the COMS RI estimates differ largely from the rain-gauge measurements. The PDF from rain gauges and COMS RI for the study periods is shown in Fig. 3(b). The PDFs of ground-based measurements and COMS RI share similar frequency distribution of precipitation rate in general. Dominating precipitation rate of both

two products during the study period was light precipitation ranged from 0 to $1 \mathrm{~mm} / \mathrm{hr}$. For the 1 to $4 \mathrm{~mm} / \mathrm{hr}$ bins, however, COMS RI shows underestimated performance in comparison with the ground-based measurement. In contrast, the COMS RI tends to present slightly overestimated frequencies in the 5 to $14 \mathrm{~mm} / \mathrm{hr}$ bins. These discrepancies might be associated with the difference in spatial support scales between the satellite and the rain gauges and the 
limitations of the infrared-based precipitation algorithm, whose estimates rely on the relationship between infrared brightness temperature and cloud characteristics (Hong et al., 2005a; Mishra et al., 2009; 2012).

The statistical results of COMS RI data evaluated at all rain gauges are presented in Table 1. The COMS RI data showed a positive ME, indicating overestimated precipitation compared to the gauge values at all 44 sites. Also, the ME and RMSE increased, whereas the r, POD, and FAR improved, with accumulation time (Table 1). The overall results agree with those of previous studies (Cheema and Bastiaanssen, 2011; Peleg et al., 2013). Chaudhari et al. (2006) compared precipitation provided by the NOAA/Climate Prediction Center in different time scales for India in 2003 and 2004, and their results showed increasing mean bias, RMSE, and mean absolute error (MAE) with increasing time steps. Liechti et al. (2012) reported that the POD estimated from the TRMM, CPC Morphing Technique (CMORPH), and the Famine Early Warning System Network's RFE2.0 product increased, whereas the FAR decreased, with increasing precipitation accumulation time. The POD and FAR in the precipitation estimates from TRMM 3B42 and Precipitation Estimation from Remote Sensing Information using Artificial Neural Network (PERSIANN) over the Poyang Lake basin, Yangtze River, also showed an increasing (decreasing) trend of POD (FAR) with an increasing time threshold ( $\mathrm{Li}$ et al., 2014). Another evaluation of four satellite-based precipitation products (TRMM 3B42, TRMM 3B42RT, CMORPH, and the Global Satellite Mapping of Precipitation) over Mainland China, reported similar error ranges for daily rainfall accumulation: RMSE of $6.21-8.06 \mathrm{~mm} / \mathrm{day}$, POD of $0.58-0.76$, and FAR of 0.34 0.51 (Qin et al., 2014). 


\subsection{Analysis of merging techniques vis-à-vis station density and temporal resolution}

Understanding how changes in rain gauge densities and accumulation time affect precipitation estimation is critical to understanding the capability of rain-gauge and satellitebased precipitation datasets (Goovaerts, 1999; Goudenhoofdt and Delobbe, 2009; Mishra, 2013). Based on these studies, the effects of rain gauge density and accumulation time were analyzed using the methodology explained in Section 3.2.

Before validating the merging techniques, inference of experimental variograms in different network densities and accumulation times were considered. During the interpolation of the 25 different scenarios, the optimized variograms were automatically selected with a maximum separation distance of $100 \mathrm{~km}$ to reflect the farthest distance among various rain gauges. Fig. 4 (a) shows the time-averaged experimental and theoretical variograms for five different scenarios. The effective ranges increased with the number of rain gauges included in the scenario, as shown in Fig. 4 (b). Sill and nugget values ranged from 14.32 to 16.83 and 0.01 to 0.1 , respectively. The optimum model parameters, including effective range, sill, and nugget estimated from different accumulation times for all rain gauge densities are presented in Fig. 4 (b). The effective range is between $74.26 \mathrm{~km}$ and $91.10 \mathrm{~km}$, with sill and nugget values from 14.32 to 16.83 and 0.03 to 0.09 , respectively. In general, increased accumulation time (i.e., an increase in temporal resolution) and rain-gauge density leads to an increased effective range in the exponential variogram model (Fig. 4). These results imply not only a good relationship between gauges but also estimation of valid precipitation. Berndt et al. (2014) and Ly et al. (2011) also observed that effective range increased with accumulation time and rain-gauge density. 
Table 2 shows the ME, RMSE, and $r$ depending on the accumulation time. The results indicate that the merged datasets showed not only lower ME and RMSE but also higher $r$ values at five different accumulation times compared with those from COMS RI presented in Table 1. The RMSE calculated from the three different merging techniques and the Kriged gauge precipitation increase with accumulation time, which is affected by the RMSE trend from COMS RI (Fig. 5). The magnitude of errors at low accumulation times amasses as the accumulation time increases (Ouma et al., 2012; Shen et al., 2010), which leads to the increased RMSE in COMS RI with increasing accumulation time. The POD and FAR results from the merged techniques were also better than those from the original COMS RI. In particular, the FARs of merged precipitations (0.071-0.38.lo6) showed greater improvements than those from COMS RI (0.500-0.702). In contrast with Fig. 5, the general trend of relative bias decreased in all four merging techniques as accumulation time increased (Fig. 6). CM showed the lowest relative bias across most accumulation time-steps, except for the accumulation times of 12 and 24 hours. The increasing trend of POD and decreasing trend of FAR (Fig. 7) also confirms that merged precipitation techniques showed improvement in detecting a rainfall event as accumulation time increased.

When network density increased, POD and FAR showed increasing and decreasing trends, respectively (Fig. 7). However, the variations of POD and FAR between the scenarios were smaller than with accumulation time. The trends of relative bias in Fig. 6 also certify that the techniques are more sensitive to variation in accumulation time than to changes in network density. The RMSE, r, and ME of the five different scenarios are summarized in Table 3. The correspondence of rainfall products resulting from all merging techniques increased as more 
rain gauges were considered for calculation. In S0, CM outperformed the other techniques considering RMSE and r. However, as the rain gauge density increased, OK produced slightly more reliable results than the other merging techniques. The FAR and RMSE in all four methods showed slight decreases, and the POD showed a slight increase with an increase in rain-gauge density. The RMSE and $\mathrm{r}$ results also imply that Kriging-based precipitation data are more reliable than the other merged products. Berndt et al. (2014) showed that the difference between the OK and CM methods, quantified by RMSE, diminished as the raingauge density increased. Ly et al. (2011) also indicated that OK estimated using more rain gauges produced a smaller RMSE than OK estimated with fewer rain gauges. This is a natural outcome if conventional variogram models (e.g., exponential, Gaussian, and spherical models) are reasonable representations of precipitation spatial variability. As the location of estimation moves farther away from the measurements, data uncertainty increases (up to the variogram range); thus with denser measurement points, overall estimation uncertainty decreases. Also, if network density is sparse, the uncertainty of the fitted variogram model would increase because of the smaller number of samples used for the semi-variance calculation (Adhikary et al., 2014).

\subsection{Evaluation of merging techniques}

\subsubsection{Spatial distribution of precipitation}

Based on the results in Tables 2 and 3, OK performed better than the merged precipitation estimates by CM, GDA and GRA, on average. However, the utility of merging satellite data with gauge measurements would be greater when the precipitation field exhibits a large 
spatial heterogeneity that cannot be effectively captured by limited rain-gauge networks. This is illustrated in the Fig. 8, which represented the daily precipitation maps for S0, S1, and S4 generated by Kriging and the three merging techniques on May 1 and May 9, 2011. These maps were compared with the Kriged precipitation estimation using all 44 sites $\left(\mathrm{OK}_{\mathrm{all}}\right)$ and the original COMS RI.

As shown Fig. 8(a), spatial distribution of the original COMS RI showed slight underestimation, even though southeastern part of study area presented similar patterns of precipitation compared with that of $\mathrm{OK}_{\text {all }}$. By comparison, as shown Fig. 8(b), the original COMS RI showed overestimated average rainfall in comparison with $\mathrm{OK}_{\text {all }}$, whereas the southern part of the study area showed similar precipitation patterns. Particularly in the northern part of the study area, COMS RI significantly overestimated precipitation compared with the Kriged map in S0 and S1. The uncertainties of the COMS RI results from its indirect estimation algorithm for precipitation, which relies on the cloud-top brightness temperature in the infrared or visible bands (Scofield and Kuligowski, 2003; Joyce et al., 2004). Tuttle et al. (2008) reported that scale problems associated with detecting cloud characteristics also contribute to large uncertainties in precipitation retrieval from satellites.

The Kriged precipitation maps from S0 and S1 in Figs. 8(a) and (b) feature isolated circular rainfall patches ("bull's eyes"), which are typically observed because of contrasting measurements from a small number of points (Yoon and Bae, 2013). Westerberg et al. (2010) noted that the problem related to low rain-gauge density could be illustrated through the bull's eyes. In contrast, as shown in the S4 scenario, the Kriged precipitation field becomes similar to $\mathrm{OK}_{\mathrm{all}}$ as the network density increases. 
The CM-based precipitation estimation describes more-specific spatial patterns than the Kriged gauge precipitation, regardless of the number of rain gauges. CM under S0 and S1 showed spatial patterns more similar with $\mathrm{OK}_{\text {all }}$ than did the other merging techniques in both days (Fig. 8). Even for S4, CM showed virtue in capturing rainfall patterns missed by the Kriged precipitation model by adopting the advantages of both gauge measurements and spatially distributed COMS RI data.

GRA- and GDA-based precipitation estimates seem to be more strongly influenced by the COMS RI than the CM-based map (Fig. 8) because of differences in the calibration procedures. The CM-based precipitation estimation compensates for ground-based precipitation data, whereas the GRA- and GDA-based precipitation data are calibrated from COMS RI. As shown in Fig. 8(a), GDA- and GRA-based precipitation estimates for S0 showed different patterns (underestimation and overestimation) compared with $\mathrm{OK}_{\text {all }}$ and CM-based precipitation estimation for S0. As shown in Fig. 8(b), the GRA- and GDA-based precipitation estimation was comparable to the CM-based estimation for S1 and S4, although they showed different patterns in S0. Duan and Bastiannsen (2013) reported that a scarcity of rain gauges could lead to low accuracy for both GDA and GRA. According to Vila et al. (2007), the GDA method showed large difference when a large distinction occurred between satellite- and ground-based precipitation data. The GRA method is difficult to compute when the value of satellite-based precipitation, ground-based precipitation, or their ratio is zero because the denominator in equation (4) becomes zero; consequently, the ratio cannot be determined.

\subsubsection{Spatial heterogeneity of precipitation}


The spatial distributions of $\mathrm{OK}$ and the three different merging techniques shown in Fig. 8 present inconsistent results, as noted in Tables 2 and 3. Those contradictory results could be caused by calculating the statistics summarized in Tables 2 and 3 using the whole datasets observed during the study period. On account of the higher FAR from remotely sensed precipitation and the superior accuracy of gauge measurements for a small spatial support, Kriged gauge precipitation data might be better than merged precipitation on average when including a large number of no-rain or homogeneous rainfall fields. To examine the effect of precipitation spatial heterogeneity on the relative merits of merging, the accuracy of the Kriged and merged fields were compared under varying spatial heterogeneity of precipitation (Fig. 9).

We defined the heterogeneity of precipitation as the spatial variance of the hourly COMS RI precipitation data. The difference in RMSE between the merging techniques and Kriging was plotted over four different spatial variances of the hourly COMS RI precipitation (i.e., thresholds as $1,5,10$, and $15 \mathrm{~mm}^{2} /$ accumulation time ${ }^{2}$ ). The COMS RI was chosen to define spatial heterogeneity because it was the main predictor for the merged precipitation and it had a consistently high statistical power regardless of the number of rain gauges. Hourly precipitation was also considered because accumulated precipitation could decrease the spatial heterogeneity with the effect of spatial smoothing.

CM showed a higher efficiency in the low-gauge density and moderately high spatial heterogeneity cases. In Fig. 9, the CM-based precipitation estimation showed a positive difference of RMSE at all four thresholds in S0 and all gauge densities with a high spatial heterogeneity (thresholds of $10-15 \mathrm{~mm}^{2} /$ accumulation time ${ }^{2}$ ). Thus, the CM-based 
precipitation estimation produced smaller RMSE values than the Kriged gauge precipitation estimation. This result has important implications for the application of merging techniques in the monitoring of spatially heterogeneous or highly localized storm events. Garcia et al. (2008) and Pluntke et al. (2010) reported the limitations of Kriging when explaining the spatial heterogeneity of rainfall events, including convective rainfall. From S1 to S4, CMbased precipitation estimations outperformed the Kriged precipitation model above 5 $\mathrm{mm}^{2} /$ accumulation time $\mathrm{e}^{2}$.

GDA, which uses the difference between ground-based and satellite-based precipitation for merging, showed a higher RMSE at low density (S0 and S1) until the threshold reached 10 $\mathrm{mm}^{2} /$ accumulation time ${ }^{2}$. However, GDA estimated more accurate precipitation when the threshold was above $10 \mathrm{~mm}^{2} /$ accumulation time $\mathrm{s}^{2}$ because the COMS precipitation field played an efficient role in detecting spatial variability. OK derived better estimates than GDA up to the $5 \mathrm{~mm}^{2} /$ accumulation time $\mathrm{m}^{2}$ threshold because of increasing network density, whereas GDA derived better estimates than Kriging when the thresholds were above 10 $\mathrm{mm}^{2} /$ accumulation time ${ }^{2}$. Similarly, GRA showed slightly higher RMSE than Kriging in S3 and S4, whereas it showed a lower RMSE than Kriging until the threshold reached 10 $\mathrm{mm}^{2} /$ accumulation time ${ }^{2}$ in S0 and S1.The poor performance of GRA in S3 and S4 might be explained through the numerical limitation of the geographical ratio used in GRA.

Overall, all three merging techniques showed reasonable performance with low gauge density and high precipitation spatial heterogeneity. In a comparison of the three methods, the performance of $\mathrm{CM}$ was superior. Of special note is that $\mathrm{CM}$ presented noticeably better performance than $\mathrm{OK}$ as the spatial variance approached $10 \mathrm{~mm}^{2} /$ accumulation time $\mathrm{e}^{2}$ or if the 
network density was low. Meanwhile, GDA and GRA showed lower performance than OK with a spatial variance below $5 \mathrm{~mm}^{2} /$ accumulation time ${ }^{2}$. Merged precipitation, however, showed better performance than Kriged precipitation when the spatial heterogeneity was at or above thresholds of $10 \mathrm{~mm}^{2} /$ accumulation time $\mathrm{m}^{2}$ with low density (S0, S1, and S2).

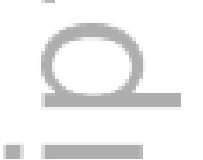

\section{Summary \& Conclusion}

The main objective of this study was evaluating methods to improve the accuracy of the COMS RI satellite precipitation product by merging it with ground-based precipitation data using three different techniques: CM, GDA, and GRA. The kriged gauge precipitation by OK was used as a control case to assess the utility of COMS RI in the merged estimations.

Consistent with previous research outputs, both statistical indicators (ME, Relative bias, r, and RMSE) and categorical statistics (POD and FAR) for the merged and Kriged precipitation fields improved as the accumulation time and gauge density increased. The improvement was more significant with increasing accumulation time than with increasing gauge density. The influence of the increasing rain-gauge density leveled off at a density that varied among the different merging methods and OK.

The impact of precipitation spatial heterogeneity on the performances of the tested techniques and OK was also examined. When the spatial variance of the COMS RI data was less than $5 \mathrm{~mm}^{2} /$ accumulation time ${ }^{2}$, OK showed better results than the merging techniques. However, the merging methods outperformed OK for spatially heterogeneous and sizeable precipitation events. Among the three different merging techniques, CM showed the best 
performance, particularly in cases of low density (S0).

The results of this study demonstrate that accurate precipitation estimates in near real-time can be produced using merging techniques for both low rain-gauge density (S0 to S2) and spatially heterogeneous rainfall events. Considering the general tendency of higher spatial heterogeneity for larger rainfall events, the merging techniques can potentially provide important skill gains in predicting water-borne natural disasters, such as floods and landslides. In particular, CM-based merging could be useful for regions with sparse rain gauges.

To further examine the practical efficacy of merged precipitation products, our merged products need to be tested for real hydrological predictions. An evaluation of near real-time flood predictions forced by various interpolated and merged precipitation products in the study site is currently under way.

\section{Acknowledgements}

The authors would like to express special thanks to the National Meteorological Satellite Center (NMSC; http://nmsc.kma.go.kr/) and Water Resources Management Information System (WAMIS; www.wamis.go.kr/) for providing Communication, Ocean and Meteorological Satellite (COMS) products and ground-based observation, respectively. This research was supported by the Space Core Technology Development Program through the National Research Foundation of Korea (NRF) funded by the Ministry of Science, ICT and Future Planning (NRF-2014M1A3A3A02034789). 


\section{References}

Adhikary, S.K., Yilmaz, A.G., Muttil, N., 2014. Optimal design of rain gauge network in the Middle Yarra River catchment, Australia. Hydrological Processes.

AghaKouchak, A., Mehran, A., Norouzi, H., Behrangi, A., 2012. Systematic and random error components in satellite precipitation data sets. Geophysical Research Letters, 39(9), L09406.

Andréassian, V., Perrin, C., Michel, C., Usart-Sanchez, I., Lavabre, J., 2001. Impact of imperfect rainfall knowledge on the efficiency and the parameters of watershed models. Journal of Hydrology, 250(1-4), 206-223.

Arthur Y. Hou, Ramesh K. Kakar, Steven Neeck, Ardeshir A. Azarbarzin, Christian D. Kummerow, Masahiro Kojima, Riko Oki, Kenji Nakamura, and Toshio Iguchi, 2014. The Global Precipitation Measurement Mission. Bull. Amer. Meteor. Soc., 95, 701-722. doi: http://dx.doi.org/10.1175/BAMSD-13-00164.1

Atlas, D., Rosenfeld, D., Wolff, D.B., 1990. Climatologically Tuned Reflectivity-Rain Rate Relations and Links to Area-Time Integrals. Journal of Applied Meteorology, 29(11), 1120-1135.

Bae, D.H., Jung, I.W., and Chang, H. (2008) Long-term trend of precipitation and runoff in Korean river basins, , Hydrol. Process., 22(14), 2644-2656

Baik, J., Choi, M., 2015. Spatio-temporal variability of remotely sensed precipitation data from COMS and TRMM: Case study of Korean peninsula in East Asia. Advances in Space Research, 56, 1125-1138. doi:10.1016/j.asr.2015.06.015.

Bárdossy, A., Lehmann, W., 1998. Spatial distribution of soil moisture in a small catchment. Part 1: geostatistical analysis. Journal of Hudsorology, 206(1-2), 1-15.

Barnes, S.L., 1973. Mesoscale objective analysis using weighted time-series observations. NOAA Tech. Memo. ERL NSSL-62, National Severe Storms Laboratory, Norman, OK, 60 pp. [NTIS COM73-10781].

Berndt, C., Rabiei, E., Haberlandt, U., 2014. Geostatistical merging of rain gauge and radar data for high temporal resolutions and various station density scenarios. Journal of Hydrology, 508, 88-101.

Blacutt, L.A., Herdies, D.L., de Gonçalves, L.G.G., Vila, D.A., Andrade, M., 2015. Precipitation comparison for the CFSR, MERRA, TRMM3B42 and Combined Scheme datasets in Bolivia. Atmospheric Research 163, 117-131.

Chaudhari, K.N., Sarkar, C., Patel, N.K., Parihar, J.S., 2006. AN INTER-COMPARISON OF SATELLITE BASED NOAA CPC RAINFALL ESTIMATES AND GAUGE OBSERVATIONS OVER SELECTED STATIONS IN INDIA, Symposium of International Society for Photogrammetry and Remote Sensing Commission IV, September 25-30, Goa, India.

Chappell, A., Renzullo, L.J., Raupach, T.H., and Haylock, M. (2013), Evaluating geostatistical 
methods of blending satellite and gauge data to estimate near real-time daily rainfall for Australia, J. Hydrol, 493, 105-114

Cheema, M.J.M., Bastiaanssen, W.G.M., 2012. Local calibration of remotely sensed rainfall from the TRMM satellite for different periods and spatial scales in the Indus Basin. International Journal of Remote Sensing, 33(8), 2603-2627.

Chen, Y., Ebêrt, E.E., Walsh, K.J.E., Davidson, N.E., 2013. Evaluation of TRMM 3B42 precipitation estimates of tropical cyclone rainfall using PACRAIN data. Journal of Geophysical Research: Atmospheres, 118(5), 2184-2196.

Cheng, K.-S., Lin, Y.-C., Liou, J.-J., 2008. Rain-gauge network evaluation and augmentation using geostatistics. Hydrological Processes, 22(14), 2554-2564.

Cohen Liechti, T., Matos, J.P., Boillat, J.L., Schleiss, A.J., 2012. Comparison and evaluation of satellite derived precipitation products for hydrological modeling of the Zambezi River Basin. Hydrology and Earth System Sciences, 16(2), 489-500.

Creutin, J.D., Delrieu, G., Lebel, T., 1988. Rain Measurement by Raingage-Radar Combination: A Geostatistical Approach. Journal of Atmospheric and Oceanic Technology, 5(1), 102-115.

Crochet, P., Jóhannesson, T., Jónsson, T., Sigurðsson, O., Björnsson, H., Pálsson, F., Barstad, I., 2007. Estimating the spatial distribution of precipitation in Iceland using a linear model of orographic precipitation. J. Hydrometeor., 8, 1285-1306.

Crosson, W.L., Claude E. Duchon, Ravikumar Raghavan, and Steven J. Goodman, 1996: Assessment of Rainfall Estimates Using a Standard Z-R Relationship and the Probability Matching Method Applied to Composite Radar Data in Central Florida. J. Appl. Meteor., 35, 1203-1219. doi: http://dx.doi.org/10.1175/1520-0450(1996)035<1203:AOREUA>2.0.CO;2.

Duan, Z., Bastiaanssen, W.G.M., 2013. First results from Version 7 TRMM 3B43 precipitation product in combination with a new downscaling-calibration procedure. Remote Sensing of Environment, $131(0), 1-13$.

Duethmann, D. et al., 2013. Evaluation of areal precipitation estimates based on downscaled reanalysis and station data by hydrological modelling. Hydrology and Earth System Sciences, 17(7), 2415-2434.

Duncan, J.M.A., Biggs, E.M., 2012. Assessing the accuracy and applied use of satellite-derived precipitation estimates over Nepal. Applied Geography, 34(0), 626-638.

Ebert, E.E., Janowiak, J.E., Kidd, C., 2007. Comparison of Near-Real-Time Precipitation Estimates from Satellite Observations and Numerical Models. Bulletin of the American Meteorological Society, $88(1), 47-64$.

Ehret, U., 2003. Rainfall and flood nowcasting in small catchments using weather radar. Ph.D Thesis Thesis, University of Stuttgart, Germany, Germany. 
Feidas, H. et al., 2009. Validation of an infrared-based satellite algorithm to estimate accumulated rainfall over the Mediterranean basin. Theor Appl Climatol, 95(1-2), 91-109.

Fornasiero, A., Bech, J., and Alberoni, P. P., 2006. Enhanced radar precipitation estimates using a combined clutter and beam blockage correction technique, Natural Hazards Earth System Sciences, 6, 697-710, doi:10.5194/nhess-6-697-2006.

Frezghi, M.S., Smithers, J., 2008. Merged rainfall fields for continuous simulation modelling (CSM). Water SA, 34(5), 523-528.

Garcia,-M., Peters-Lidard, C.D., Goodrich, D.C., 2008. Spatial interpolation of precipitation in a dense gauge network for monsoon storm events in the southwestern United States. Water Resources Research, 44(5), W05S13.

Germann, U., Galli, G., Boscacci, M. and Bolliger, M., 2006. Radar precipitation measurement in a mountainous region. Q.J.R. Meteorol. Soc., 132, 1669-1692. doi: 10.1256/qj.05.190.

Gilberto A. Vicente, Roderick A. Scofield, and W. Paul Menzel, 1998: The Operational GOES Infrared Rainfall Estimation Technique. Bull. Amer. Meteor. Soc., 79, 1883-1898. doi: http://dx.doi.org/10.1175/1520-0477(1998)079<1883:TOGIRE>2.0.CO;2.

Goovaerts, P., 1999. Using elevation to aid the geostatistical mapping of rainfall erosivity. Catena, 34(3-4), 227-242.

Goovaerts, P., 2000. Geostatistical approaches for incorporating elevation into the spatial interpolation of rainfall. Journal of Hydrology, 228(1-2), 113-129.

Goudenhoofdt, E., Delobbe, L., 2009. Evaluation of radar-gauge merging methods for quantitative precipitation estimates. Hydrol. Earth Syst. Sci., 13(2), 195-203.

Hong, G., Heygster, G., Miao, J., Kunzi, K., 2005a. Detection of tropical deep convective clouds from AMSU-B water vapor channels measurements. Journal of Geophysical Research D: Atmospheres, $110(5), 1-15$.

Hong, Y., Hsu, K.-1., Moradkhani, H., Sorooshian, S., 2006. Uncertainty quantification of satellite precipitation estimation and Monte Carlo assessment of the error propagation into hydrologic response. Water Resources Research, 42(8), W08421.

Huang, Y., Chen, S., Cao, Q., Hong, Y., Wu, B., Huang, M., Qiao, L., Zhang, Z., Li, Z., Li, W., Yang, X., 2014. Evaluation of Version-7 TRMM Multi-Satellite Precipitation Analysis Product during the Beijing Extreme Heavy Rainfall Event of 21 July 2012. Water, 6, 32-44, doi:10.3390/w6010032.

Huffman, G. J., David T. Bolvin, Eric J. Nelkin, David B. Wolff, Robert F. Adler, Guojun Gu, Yang Hong, Kenneth P. Bowman, and Erich F. Stocker, 2007. The TRMM Multisatellite Precipitation Analysis (TMPA): Quasi-Global, Multiyear, Combined-Sensor Precipitation Estimates at Fine Scales. J. Hydrometeor, 8, 38-55, doi: http://dx.doi.org/10.1175/JHM560.1.

Huffman, G.J., Bolvin, D.T., Braithwaite, D., Hsu, K., Joyce, R., Xie, P., Yoo, S.-H., 2013. NASA 
Global Precipitation Measurement (GPM) Integrated Multi-satellitE Retrievals for GPM (IMERG), Algorithm theoretical basis document, version 4.1. NASA.

Hudson, G. and Wackernagel, H. 1994. Mapping temperature using kriging with external drift: Theory and an example from scotland. Int. J. Climatol., 14, 77-91. doi: 10.1002/joc.3370140107.

Hwang, Y., Clark, M., Rajagopalan, B., 2011. Use of daily precipitation uncertainties in streamflow simulation and forecast. Stoch Environ Res Risk Assess, 25(7), 957-972.

Jameson, A. R. and Kostinski, A. B. 2002. Spurious power-law relations among rainfall and radar parameters. Quarterly Journal of the Royal Meteorological Society, 128., 2045-2058. doi: $10.1256 / 003590002320603520$.

Javanmard, S., Yatagai, A., Nodzu, M. I., BodaghJamali, J., and Kawamoto, H., 2010. Comparing high-resolution gridded precipitation data with satellite rainfall estimates of TRMM_3B42 over Iran, Adv. Geosci., 25, 119-125, doi:10.5194/adgeo-25-119-2010.

Jia, S., Zhu, W., Lü, A., Yan, T., 2011. A statistical spatial downscaling algorithm of TRMM precipitation based on NDVI and DEM in the Qaidam Basin of China. Remote Sensing of Environment, 115(12), 3069-3079.

Joyce, R.J., Janowiak, J.E., Arkin, P.A., Xie, P., 2004. CMORPH: A Method that Produces Global Precipitation Estimates from Passive Microwave and Infrared Data at High Spatial and Temporal Resolution. Journal of Hydrometeorology, 5(3), 487-503.

Jung, I.W., Bae, D.H., and Lee, B.J. (2012) Possible change in Korean streamflow seasonality based on multi-model climate projections, Hydrol. Process., doi: 10.1002/hyp.9215

Kidd, C., Kniveton, D.R., Todd, M.C., Bellerby, T.J., 2003. Satellite Rainfall Estimation Using Combined Passive Microwave and Infrared Algorithms. Journal of Hydrometeorology, 4(6), 10881104.

Kim, S., C. K. Park, and M. K. Kim, 2005. The regime shift of northern hemisphere circulation responsible for the spring drought in Korea, J. Korean Meteor. Soc., 41, 571-585 (in Korean with English abstract).

Krajewski, W.F., 1987. Cokriging radar-rainfall and rain gage data. Journal of Geophysical Research: Atmospheres, 92(D8), 9571-9580.

Kuligowski, R. J., 2002. A Self-Calibrating Real-Time GOES Rainfall Algorithm for Short-Term Rainfall Estimates. J. Hydrometeor, 3, 112-130, doi: http://dx.doi.org/10.1175/15257541(2002)003<0112:ASCRTG>2.0.CO;2.

Laurent, L., Audois, P., Marie-Joseph, I., Becker, M., Seyler, F., 2013. Calibration of TRMM 3B42 with Geographical Differential Analysis over North Amazonia, Geoscience and Remote Sensing Symposium (IGARSS), 2013 IEEE International, pp. 2234-2237.

Lee, D.-I., Ryu, C.-S., 2012. A Comparative Study of Rain Intensities Retrieved from Radar and 
Satellite Observations: Two Cases of Heavy Rainfall Events by Changma and Bolaven (TY15). Journal of the Korean Earth Science Society, 33(7), 569-582.

Levizzani, V. et al., 2001. Precipitation estimations from geostationary orbit and prospects for METEOSAT Second Generation. Meteorological Applications, 8(1), 23-41.

Li, M., Shao, Q., 2010. An improved statistical approach to merge satellite rainfall estimates and raingauge data. Journal of Hydrology, 385(1-4), 51-64.

Lloyd, C.D., 2005. Assessing the effect of integrating elevation data into the estimation of monthly precipitation in Great Britain. Journal of Hydrology, 308(1-4), 128-150.

Ly, S., Charles, C., Degré, A., 2011. Geostatistical interpolation of daily rainfall at catchment scale: the use of several variogram models in the Ourthe and Ambleve catchments, Belgium. Hydrol. Earth Syst. Sci., 15(7), 2259-2274.

Maki M, Maesaka T, Misumi R, Iwanami K, Suzuki S, Kato A, Shimizu S, Kieda K, Yamada T, Hirano H, Kobayahi F, Masuda A, Moriya T, Suzuki Y, Takahori A, Lee DI, Kim DS, Chandrasekar V, Wang Y. 2008. X-band polarimetric radar network in the Tokyo metropolitan area. Preprints: Proceeding of the 5th European Conference on Radar in Meteorology and Hydrology 30 June -4 July 2008, Helsinki, Finland.

Müller, M.F., Thompson, S.E., 2013. Bias adjustment of satellite rainfall data through stochastic modeling: Methods development and application to Nepal. Advances in Water Resources, 60(0), 121134.

Mecikalski, J. R., and K. M. Bedka, 2006. Forecasting convective initiation by monitoring the evolution of moving convection in daytime GOES imagery. Mon. Wea. Rev. 134, 49-78.

Michaelides, S.C., 2008. Precipitation: Advances in Measurement, Estimation and Prediction: Advances in Measurement, Estimation, and Prediction. Springer Science \& Business Media.

Mishra, A., 2013. Effect of rain gauge density over the accuracy of rainfall: a case study over Bangalore, India. SpringerPlus, 2(1), 1-7.

Mishra, A., Gairola, R., Agarwal, V., 2012. Rainfall Estimation from Combined Observations Using KALPANA-IR and TRMM- Precipitation Radar Measurements over Indian Region. J Indian Soc Remote Sens, 40(1), 65-74.

Mishra, A., Gairola, R.M., Varma, A.K., Agarwa, V.K., 2009. Study of Intense Heavy Rainfall Events over India Using KALPANA-IR and TRMMPrecipitation Radar Observations. Current Science, 9(5), 689-695.

Nalder, I.A., Wein, R.W., 1998. Spatial interpolation of climatic Normals: test of a new method in the Canadian boreal forest. Agricultural and Forest Meteorology, 92(4), 211-225.

Nasrollahi, N., 2015. False Alarm in Satellite Precipitation Data, Improving Infrared-Based Precipitation Retrieval Algorithms Using Multi-Spectral Satellite Imagery. Springer Theses. Springer 
International Publishing, pp. 7-12.

Ochoa, A., Pineda, L., Crespo, P., Willems, P., 2014. Evaluation of TRMM 3B42 precipitation estimates and WRF retrospective precipitation simulation over the Pacific-Andean region of Ecuador and Peru. Hydrol. Earth Syst. Sci., 18(8), 3179-3193.

Ouma, Y.O., Owiti, T., Kipkorir, E., Kibiiy, J., Tateishi, R., 2012. Multitemporal comparative analysis of TRMM-3B42 satellite-estimated rainfall with surface gauge data at basin scales: daily, decadal and monthly evaluations. International Journal of Remote Sensing, 33(24), 7662-7684.

Peleg, N., Ben-Asher, M., Morin, E., 2013. Radar subpixel-scale rainfall variability and uncertainty: lessons learned from observations of a dense rain-gauge network. Hydrol. Earth Syst. Sci., 17(6), 2195-2208.

Pluntke, T., Jatho, N., Kurbjuhn, C., Dietrich, J., Bernhofer, C., 2010. Use of past precipitation data for regionalisation of hourly rainfall in the low mountain ranges of Saxony, Germany. Natural Hazards and Earth System Science, 10(2), 353-370.

Qin, Y., Chen, Z., Shen, Y., Zhang, S., Shi, R., 2014. Evaluation of satellite rainfall estimates over the Chinese Mainland. Remote Sensing, 6(11), 11649-11672.

Robinson, T.P., Metternicht, G., 2006. Testing the performance of spatial interpolation techniques for mapping soil properties. Computers and Electronics in Agriculture, 50(2), 97-108.

Rozante, J.R., Moreira, D.S., de Goncalves, L.G.G., Vila, D.A., 2010. Combining TRMM and Surface Observations of Precipitation: Technique and Validation over South America. Weather and Forecasting, 25(3), 885-894.

Šálek, M., Novák, P., Seo, D., 2004. Operational application of combined radar and raingauges precipitation estimation at the CHMI, Proceedings of European Conference on Radar in Meteorology (ERAD), pp. 16-20.

Scofield, R.A., Kuligowski, R.J., 2003. Status and Outlook of Operational Satellite Precipitation Algorithms for Extreme-Precipitation Events. Weather and Forecasting, 18(6), 1037-1051.

Sene, K., 2013. Flash floods: Forecasting and warning. Springer Science \& Business Media.

Shen, Y., A. Xiong, Y. Wang, and P. Xie, 2010. Performance of high-resolution satellite precipitation products over China, J. Geophys. Res., 115, D02114, doi:10.1029/2009JD012097.

Shin, D.-B., J.-H. Kim, and H.-J. Park 2011. Agreement between monthly precipitation estimates from TRMM satellite, NCEP reanalysis, and merged gauge-satellite analysis, J. Geophys. Res., 116, D16105, doi:10.1029/2010JD015483.

Sinclair, S., Pegram, G., 2005. Combining radar and rain gauge rainfall estimates using conditional merging. Atmospheric Science Letters, 6(1), 19-22.

Tuttle, J.D., Carbone, R.E., Arkin, P.A., 2008. Comparison of Ground-Based Radar and 
Geosynchronous Satellite Climatologies of Warm-Season Precipitation over the United States. Journal of Applied Meteorology and Climatology, 47(12), 3264-3270.

Vila, D.A., de Goncalves, L.G.G., Toll, D.L., Rozante, J.R., 2009. Statistical Evaluation of Combined Daily Gauge Observations and Rainfall Satellite Estimates over Continental South America. Journal of Hydrometeorology, 10(2), 533-543.

Vulpiani, G., M. Montopoli, L. D. Passeri, A. Gioia, P. Giordano, and F. S. Marzano, 2012. On the use of dual-polarized C-band radar for operational rainfall retrieval in mountainous areas. J. Appl. Meteor and Clim., 51, 405-425.

Westerberg, I. et al., 2010. Precipitation data in a mountainous catchment in Honduras: quality assessment and spatiotemporal characteristics. Theor Appl Climatol, 101(3-4), 381-396.

Woldemeskel, F.M., Sivakumar, B., Sharma, A., 2013. Merging gauge and satellite rainfall with specification of associated uncertainty across Australia. Journal of Hydrology, 499(0), 167-176.

Wright, Daniel B, James A Smith, Gabriele Villarini, and Mary Lynn Baeck. 2013. Estimating the frequency of extreme rainfall using weather radar and stochastic storm transposition. Journal of Hydrology 488, 150-165.

Xie, P., and A.-Y. Xiong. 2011. A conceptual model for constructing high-resolution gauge-satellite merged precipitation analyses, J. Geophys. Res., 116, D21106, doi:10.1029/2011JD016118.

Xue, X. et al., 2013. Statistical and hydrological evaluation of TRMM-based Multi-satellite Precipitation Analysis over the Wangchu Basin of Bhutan: Are the latest satellite precipitation products 3B42V7 ready for use in ungauged basins? Journal of Hydrology, 499(0), 91-99.

Yoon, S.-S., Bae, D.-H., 2013. Optimal Rainfall Estimation by Considering Elevation in the Han River Basin, South Korea. Journal of Applied Meteorology and Climatology, 52(4), 802-818.

You, C.-H., Kang, M.-Y., Lee, D.-I. and Uyeda, H., 2014. Rainfall estimation by S-band polarimetric radar in Korea. Part I: preprocessing and preliminary results. Met. Apps, 21: 975-983. doi: 10.1002/met.1454.

Zhuge, X.Y., Jian, G., Fan, Y., Yuan, W., 2015. A New Satellite-Based Indicator for Estimation of the Western North Pacific Tropical Cyclone Current Intensity. Geoscience and Remote Sensing, IEEE Transactions on, 53(10), 5661-5676.

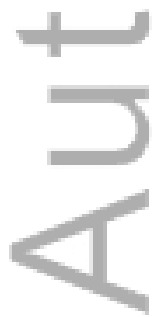




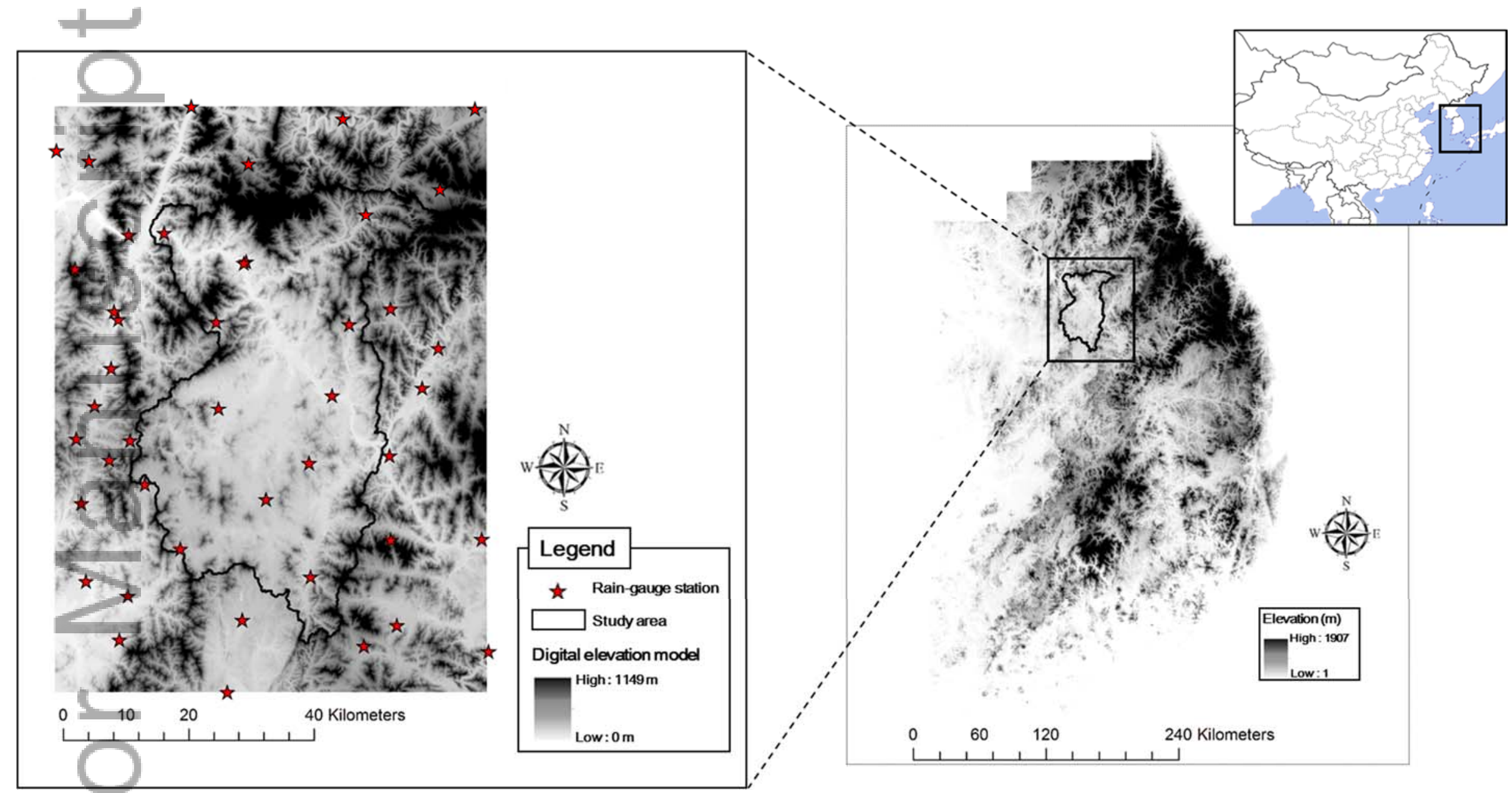

Fig. 1. Location map of Downstream of Namhan River watershed showing distribution and locations of 44 rain-gauge stations.

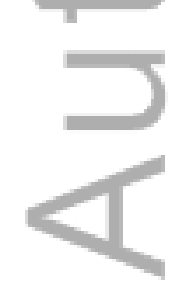



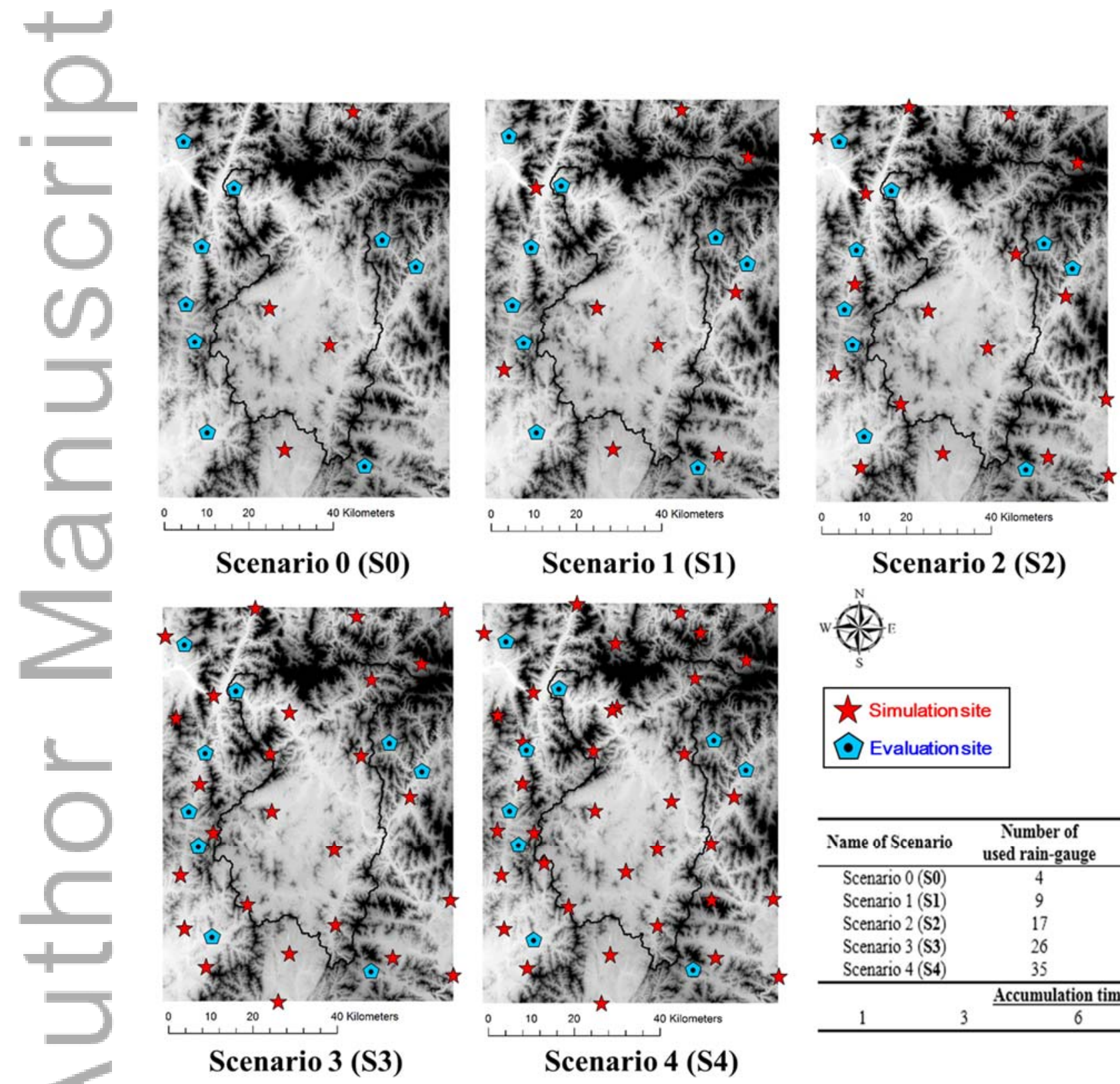

Fig. 2. Random selection of rain-gauge for different density scenarios. Asterisk and pentagon shape means stations used for merging and validation at each scenario, respectively.

This article is protected by copyright. All rights reserved. 


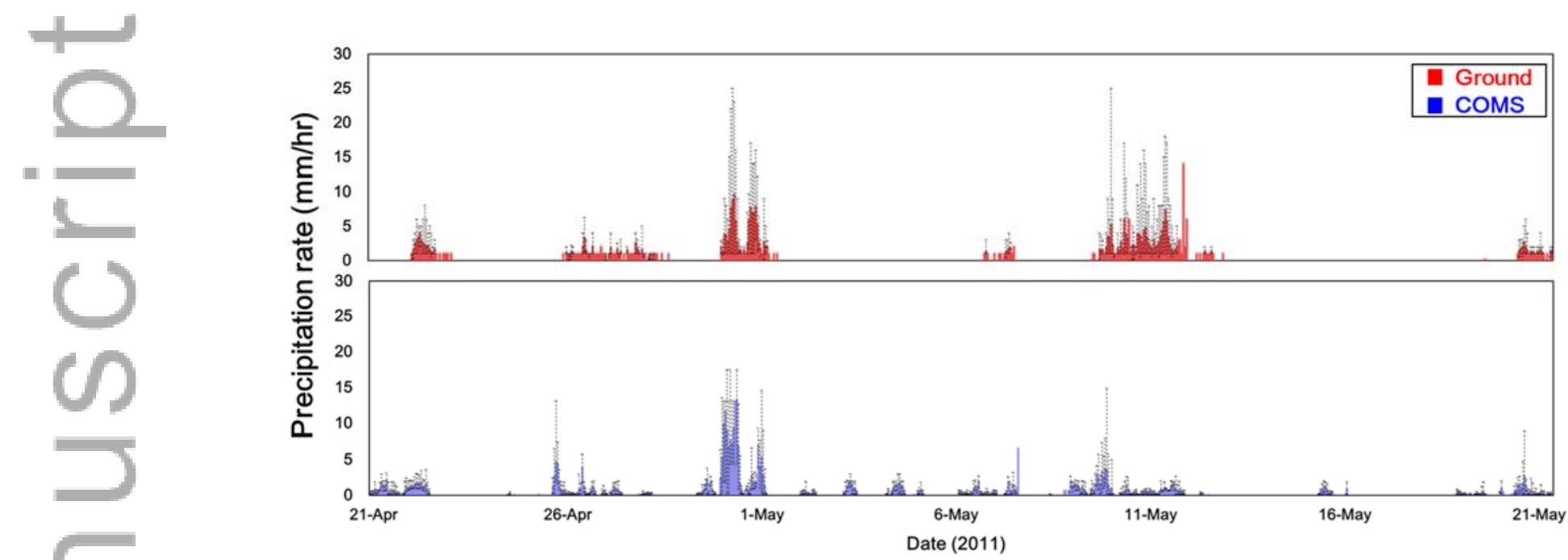

(a) Time series
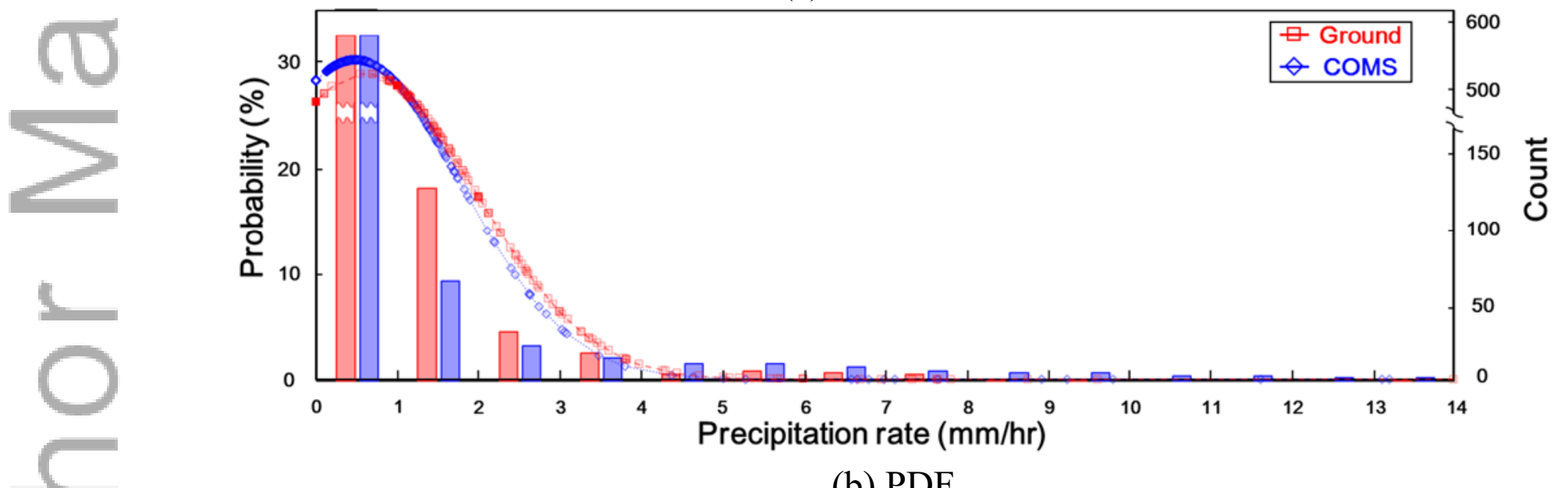

(b) PDF

Fig. 3. Time series and probability distribution function (PDF) of the mean hourly precipitation from rain-gauge and COMS RI over study periods (April 21 to May 21, 2011) at 44 sites: error bars of the time series are maximum and minimum precipitation at each products. 


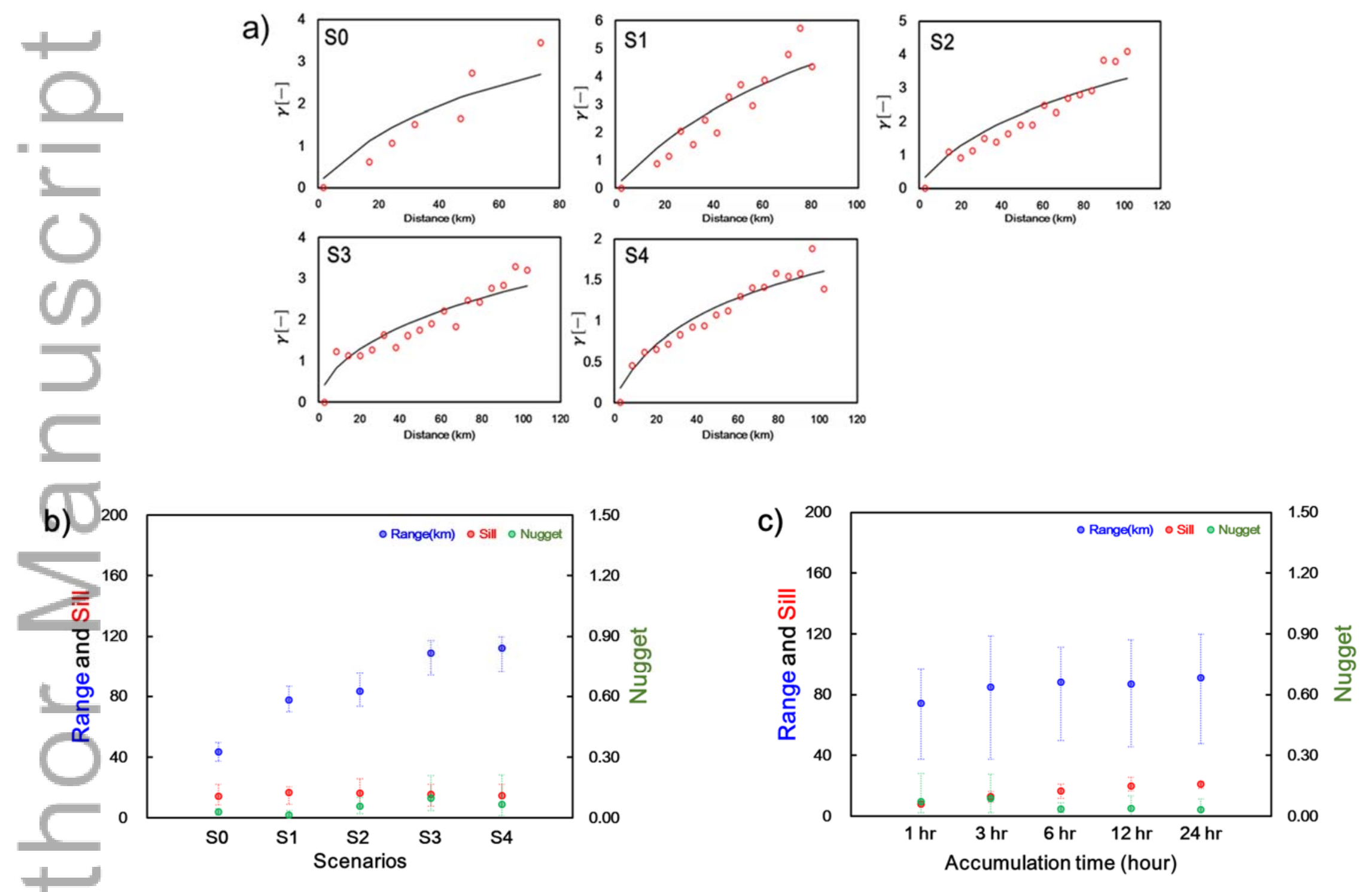

Fig. 4. (a) Time-averaged experimental and theoretical variograms for each scenario. (b) Optimum values for each accumulation time (scenario-averaged) (c) Optimum values for each scenario (time-averaged) 


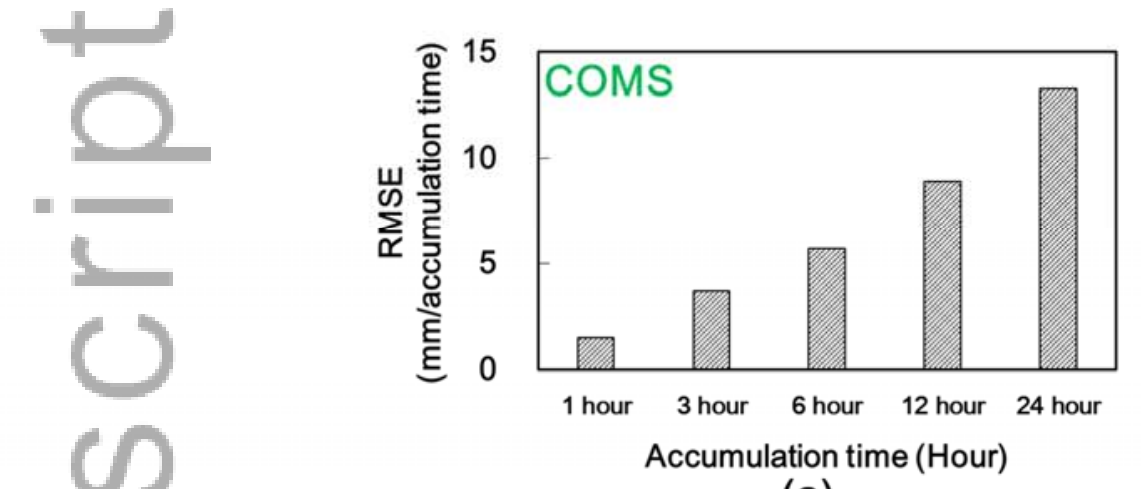

(a)

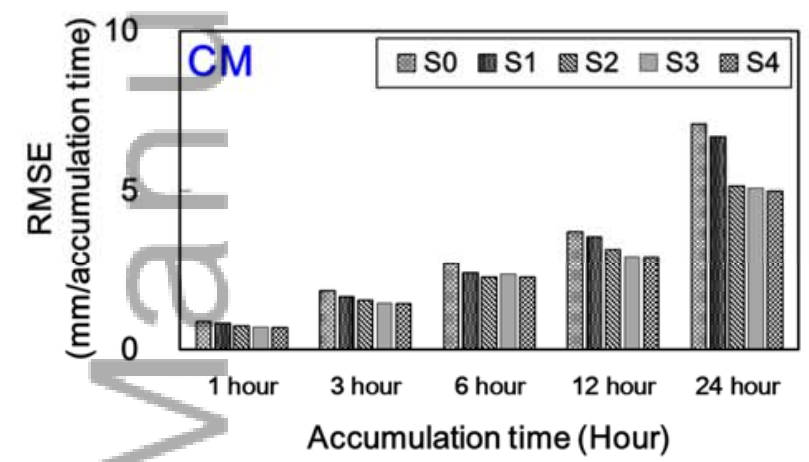

(c)

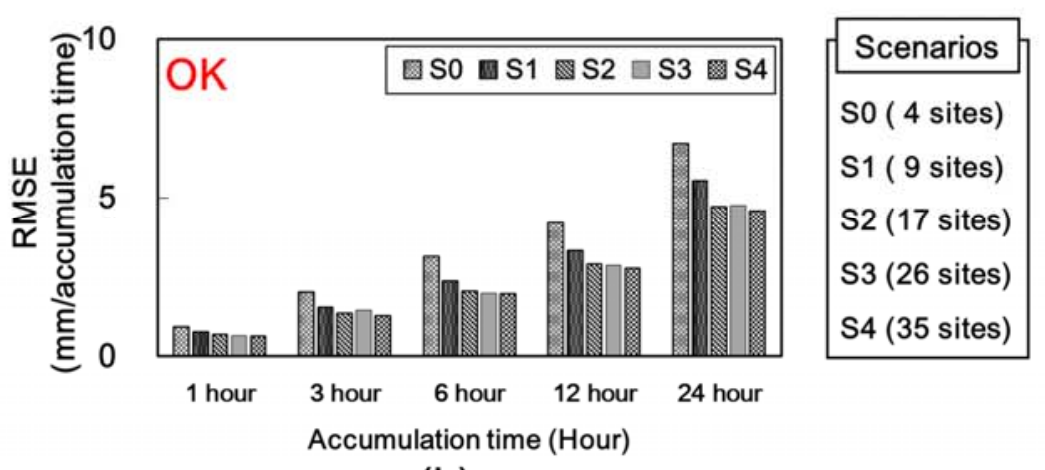

(b)

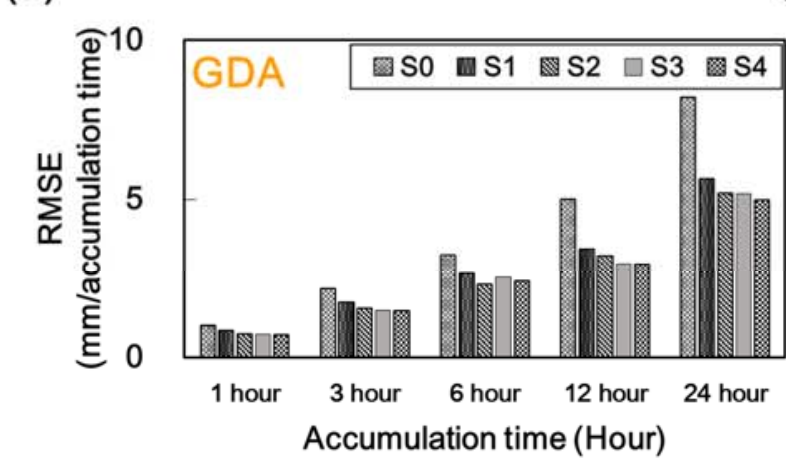

(d)

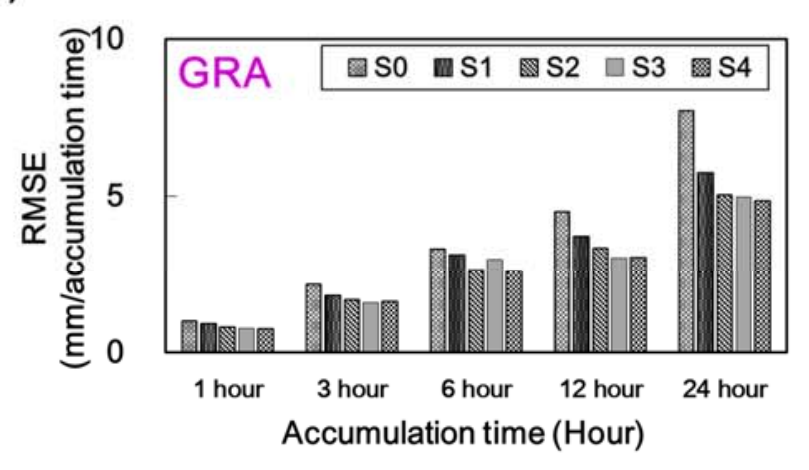

(e)

Fig. 5. RMSE performance for COMS, OK, CM, GDA, and GRA for each accumulation time and scenario. 

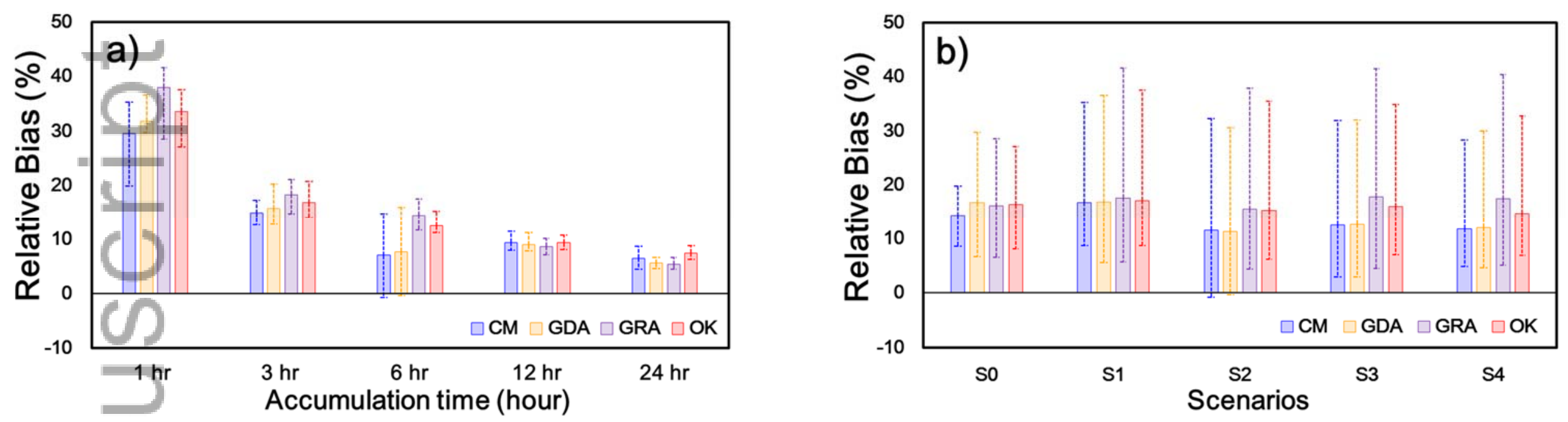

Fig. 6. Relative Bias for OK, CM, GDA, and GRA: (a) accumulation time averaged for each scenario; (b) scenario averaged for each accumulation time. Error bars are maximum and minimum value at each case. 


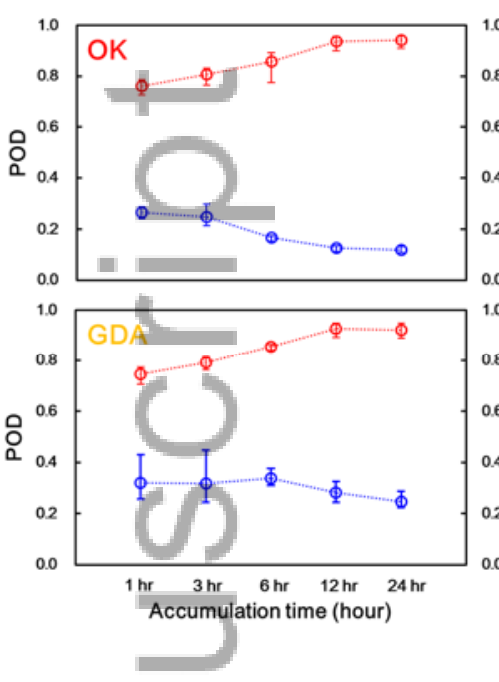

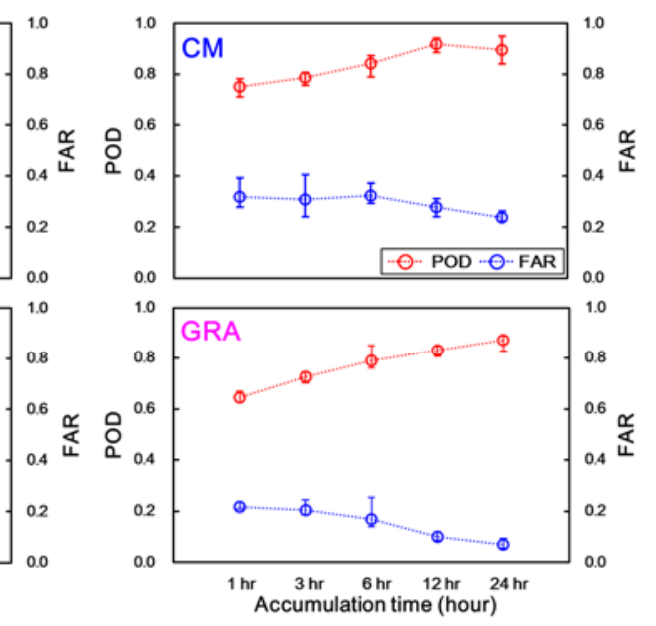

a)

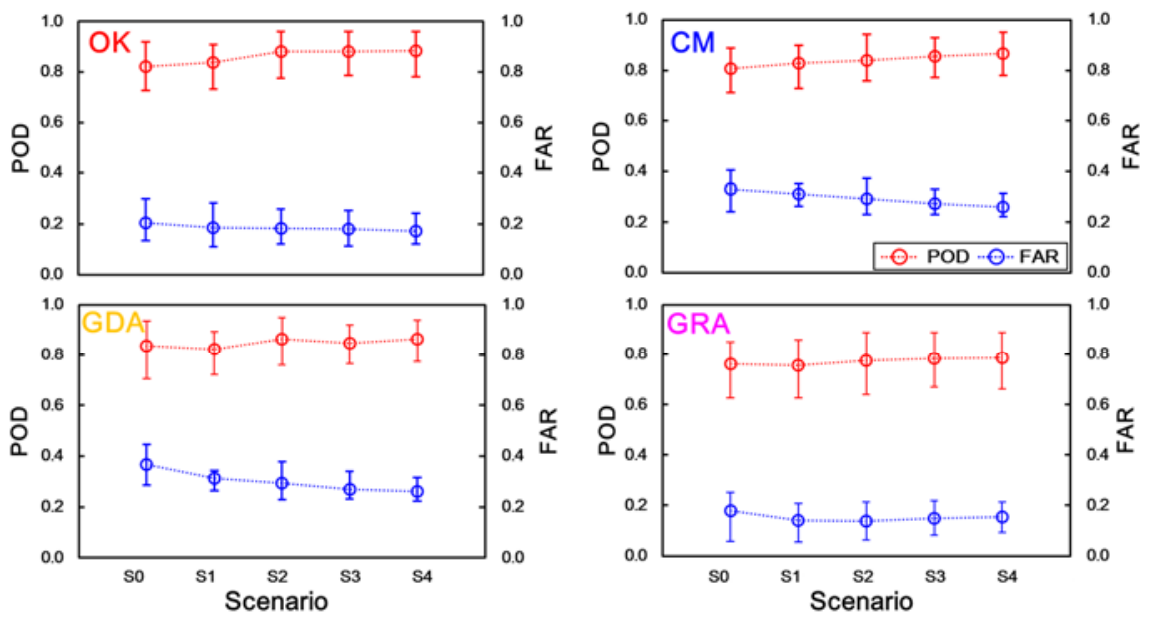

b)

Fig. 7. POD and FAR performances for OK, CM, GDA, and GRA for each (a) accumulation time and (b) scenario. Error bars are maximum and minimum precipitation at each accumulation time and scenario. 


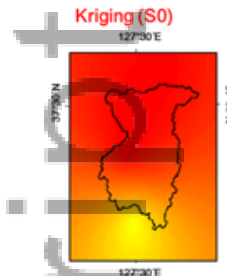

Kriging (All Sites)
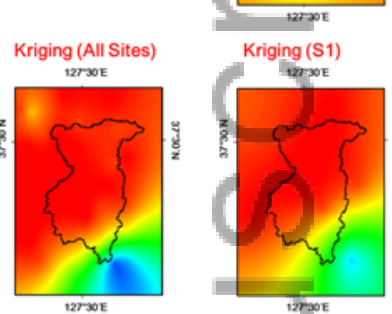

$1200 \%$
Kriging(S4)

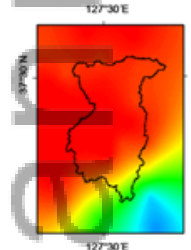

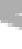

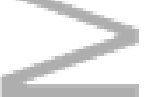

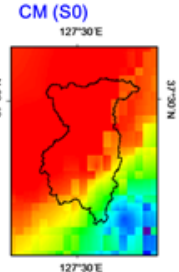

CM (S1)

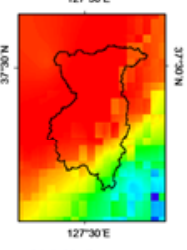

$\mathrm{CM}$ (S4)

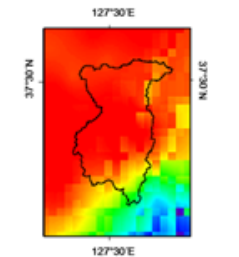

10

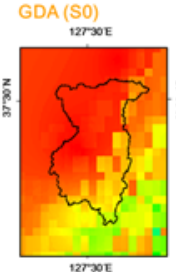

GDA(S1)

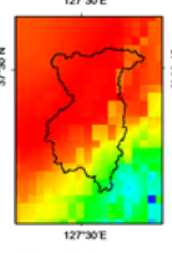

GDA (S4)

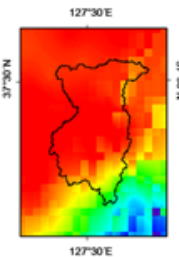

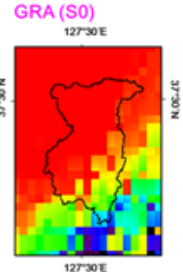

GRA (S1)

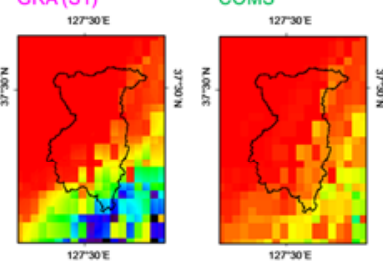

GRA (S4)

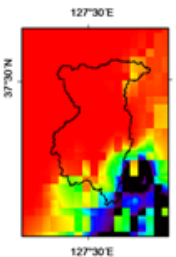

(a) May 1, 2011

20 mm/accumulation time
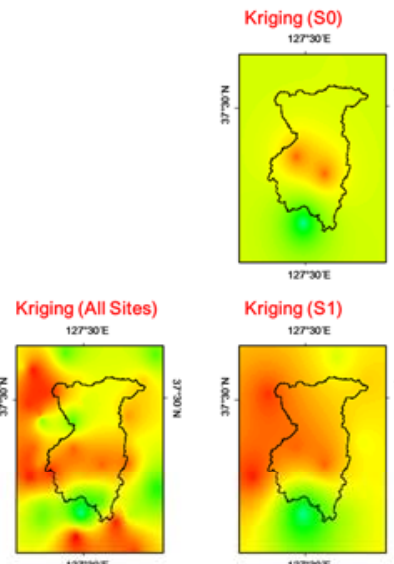

$\underset{\substack{\text { Kriging (S1) } \\ \text { 12rove }}}{\operatorname{rat}}$

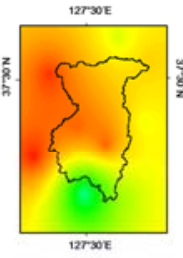

Kriging (S4)

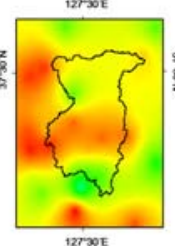

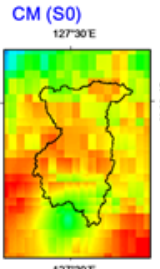

CM (S1)

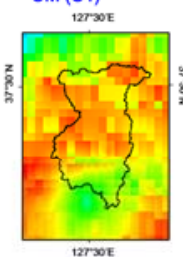

CM (S4)

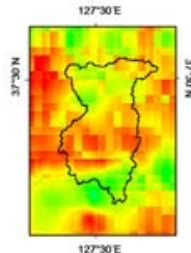

0
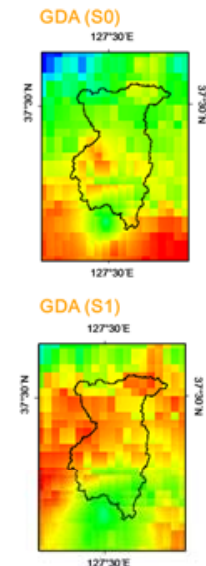

GDA(S4)
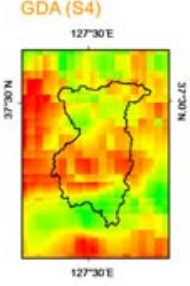

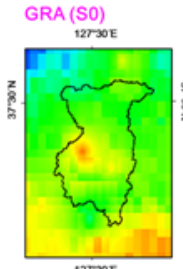

GRA(S1)

coms

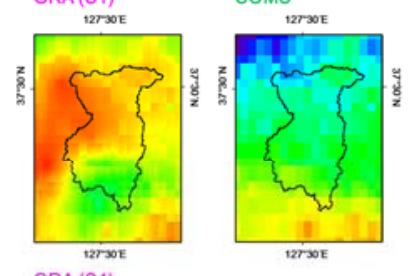

GRA (S4)

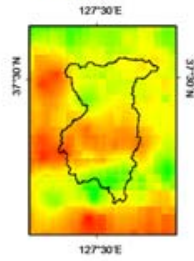

(b) May 9, 2011

Fig. 8. Spatial distribution of precipitation for temporal resolution (24 hour) on (a) May 1 and (b) May 9, 2011. Red asterisk shape is stations used for merging at each scenarios.

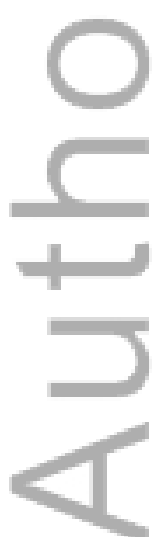




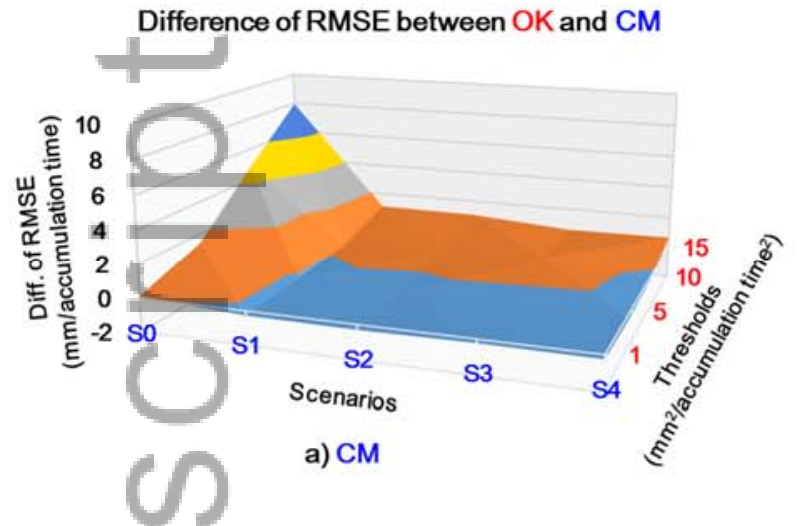

Difference of RMSE between OK and GDA

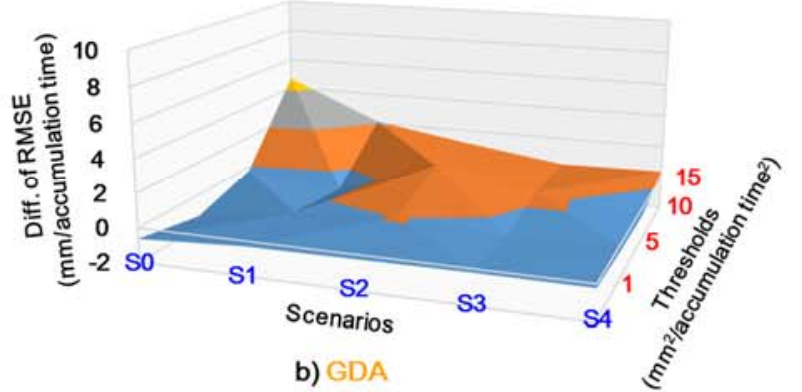

$=-2-0 \quad \equiv 0-2 \quad=2-4 \quad=4-6 \quad \equiv 6-8 \quad=8-10$
Difference of RMSE between OK and GRA

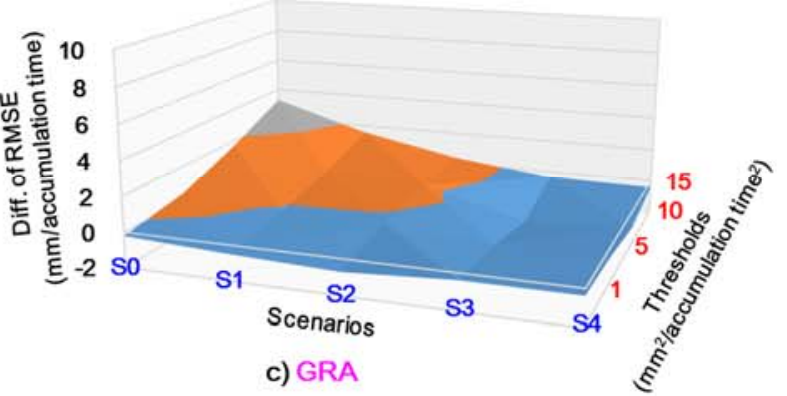

Fig. 9. Difference of RMSE between OK and merging techniques (CM, GDA and GRA) of each scenarios on different precipitation thresholds. Thresholds represents the spatial heterogeneity based on the variance $\left[9 \%\right.$ tile $\left.\left(1 \mathrm{~mm}^{2} / \text { accumulation time }\right)^{2}\right), 5 \%$ tile $(5$ $\mathrm{mm}^{2} /$ accumulation time $\left.^{2}\right), 2 \%$ tile $\left(10 \mathrm{~mm}^{2} /\right.$ accumulation time $\left.^{2}\right)$ and $1 \%$ tile $\left(15 \mathrm{~mm}^{2} /\right.$ accumulation time $\left.\left.^{2}\right)\right]$. 
Table 1. Validation statistics of COMS RI for all rain-gauges.

\begin{tabular}{|c|c|c|c|c|c|}
\hline \multirow[b]{2}{*}{$= \pm$} & \multicolumn{5}{|c|}{ Accumulation time (Hour) } \\
\hline & 1 & 3 & 6 & 12 & 24 \\
\hline ME & 0.091 & 0.272 & 0.544 & 1.087 & 2.175 \\
\hline RMSE & 1.487 & 3.715 & 5.699 & 9.407 & 13.258 \\
\hline $\mathrm{r}$ & 0.342 & 0.413 & 0.543 & 0.647 & 0.713 \\
\hline POD & 0.627 & 0.707 & 0.790 & 0.835 & 0.909 \\
\hline FAR & 0.702 & 0.674 & 0.616 & 0.567 & 0.500 \\
\hline
\end{tabular}

Note: The ME and RMSE have unit mm/accumulation time.
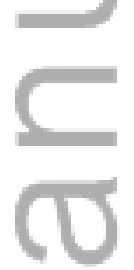

Table 2. Average merging methods performance over all scenarios for each accumulation time.

\begin{tabular}{cc|ccccc}
\hline & & \multicolumn{5}{c}{ Accumulation time (Hour) } \\
\hline \multirow{2}{*}{ OK } & & 1 & 3 & 6 & 12 & 24 \\
& ME & -0.017 & -0.057 & -0.107 & -0.200 & -0.416 \\
& RMSE & $\mathbf{0 . 6 8 0}$ & $\mathbf{1 . 4 1 1}$ & $\mathbf{2 . 0 9 8}$ & $\mathbf{2 . 9 7 6}$ & $\mathbf{4 . 9 0 3}$ \\
& $\mathrm{r}$ & 0.756 & 0.842 & 0.850 & 0.905 & $\mathbf{0 . 9 1 9}$ \\
\hline $\mathbf{C M}$ & ME & 0.016 & $\mathbf{- 0 . 0 0 1}$ & 0.034 & -0.085 & -0.264 \\
& $\mathrm{RMSE}$ & 0.772 & 1.590 & 2.401 & 3.254 & 5.802 \\
& $\mathrm{r}$ & $\mathbf{0 . 7 6 3}$ & $\mathbf{0 . 8 5 1}$ & $\mathbf{0 . 8 6 6}$ & $\mathbf{0 . 9 0 9}$ & 0.890 \\
\hline \multirow{2}{*}{ GDA } & ME & $\mathbf{0 . 0 1 2}$ & -0.003 & $\mathbf{0 . 0 3 3}$ & $\mathbf{- 0 . 0 6 6}$ & $\mathbf{- 0 . 2 0 3}$ \\
& $\mathrm{RMSE}$ & 0.803 & 1.672 & 2.617 & 3.497 & 5.835 \\
& $\mathrm{r}$ & 0.740 & 0.832 & 0.849 & 0.896 & 0.890 \\
\hline \multirow{2}{*}{ GRA } & ME & -0.038 & -0.079 & -0.132 & -0.144 & -0.306 \\
& $\mathrm{RMSE}$ & 0.857 & 1.770 & 2.927 & 3.525 & 5.663 \\
& $\mathrm{r}$ & 0.699 & 0.816 & 0.756 & 0.891 & 0.899 \\
\hline
\end{tabular}

Note: The ME and RMSE have unit $\mathbf{m m}$ /accumulation time.

This article is protected by copyright. All rights reserved. 
Table 3. Average merging methods performance over all accumulation time for each scenarios.

\begin{tabular}{|c|c|c|c|c|c|}
\hline \multirow[t]{2}{*}{ min } & \multirow[b]{2}{*}{ Scenario 0 (S0) } & \multicolumn{4}{|c|}{$\underline{\text { Scenarios }}$} \\
\hline & & Scenario $1(\mathrm{~S} 1)$ & Scenario $2(\mathrm{~S} 2)$ & Scenario 3 (S3) & Scenario 4 (S4) \\
\hline \multirow{3}{*}{ OK RMSE } & -0.188 & -0.200 & -0.134 & -0.156 & -0.148 \\
\hline & 3.411 & 2.717 & 2.346 & 2.341 & 2.250 \\
\hline & 0.783 & 0.852 & 0.879 & 0.879 & 0.885 \\
\hline \multirow{3}{*}{ CM RMSE } & -0.112 & -0.113 & -0.039 & -0.017 & -0.019 \\
\hline & 3.242 & 3.026 & 2.572 & 2.513 & 2.465 \\
\hline & 0.827 & 0.852 & 0.863 & 0.871 & 0.873 \\
\hline \multirow{3}{*}{$\begin{array}{ll} & \text { ME } \\
\text { GDA } & \text { RMSE }\end{array}$} & -0.070 & -0.067 & -0.050 & -0.025 & -0.015 \\
\hline & 3.919 & 2.849 & 2.593 & 2.568 & 2.495 \\
\hline & 0.755 & 0.855 & 0.862 & 0.868 & 0.871 \\
\hline \multirow{3}{*}{$\begin{array}{cc}\text { GRA } & \text { ME } \\
& \text { RMSE } \\
& r\end{array}$} & -0.165 & -0.144 & -0.109 & -0.147 & -0.133 \\
\hline & 3.735 & 3.061 & 2.705 & 2.664 & 2.577 \\
\hline & 0.760 & 0.816 & 0.803 & 0.845 & 0.852 \\
\hline
\end{tabular}

Note: The ME and RMSE have unit $\mathbf{m m}$ /accumulation time.

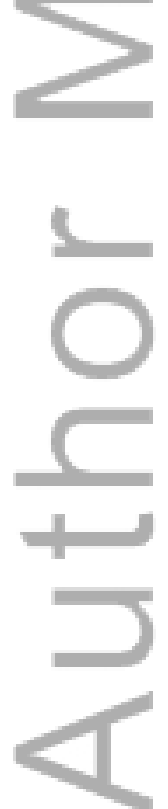




\section{University Library}

\section{- M M N E R VA A gateway to Melbourne's research publications}

Minerva Access is the Institutional Repository of The University of Melbourne

Author/s:

Baik, J;Park, J;Ryu, D;Choi, M

Title:

Geospatial blending to improve spatial mapping of precipitation with high spatial resolution by merging satellite- and ground based data

Date:

2016-01

\section{Citation:}

Baik, J., Park, J., Ryu, D. \& Choi, M. (2016). Geospatial blending to improve spatial mapping of precipitation with high spatial resolution by merging satellite- and ground based data. Hydrological Processes, 30 (16), pp.2789-2803. https://doi.org/10.1002/hyp.10786.

Persistent Link:

http://hdl.handle.net/11343/290776 